\title{
Nuclear Arc Interacts with the Histone Acetyltransferase Tip60 to Modify H4K12 Acetylation ${ }^{1,2,3}$
}

\author{
(D) Caroline L. Wee, ${ }^{1, *}$ (DShaun Teo, ${ }^{1, *}$ Nicodemus E. Oey, ${ }^{1, *}$ Graham D. Wright, ${ }^{2}$ Hendrika M.A. \\ VanDongen, ${ }^{1}$ and ${ }^{-}$Antonius M.J. VanDongen ${ }^{1}$
}

DOI:http://dx.doi.org/10.1523/ENEURO.0019-14.2014

${ }^{1}$ Program in Neuroscience and Behavioral Disorders, Duke-NUS Graduate Medical School, Singapore 169857, ${ }^{2}$ Institute of Medical Biology, a*STAR, Singapore 138648

\begin{abstract}
Arc is an immediate-early gene whose genetic ablation selectively abrogates long-term memory, indicating a critical role in memory consolidation. Although Arc protein is found at synapses, it also localizes to the neuronal nucleus, where its function is less understood. Nuclear Arc forms a complex with the $\beta$-spectrin isoform $\beta$ SpIV $\Sigma 5$ and associates with PML bodies, sites of epigenetic regulation of gene expression. We report here a novel interaction between Arc and Tip60, a histone-acetyltransferase and subunit of a chromatin-remodelling complex, using biochemistry and super-resolution microscopy in primary rat hippocampal neurons. Arc and $\beta$ SpIV $\Sigma 5$ are recruited to nuclear Tip60 speckles, and the three proteins form a tight complex that localizes to nuclear perichromatin regions, sites of transcriptional activity. Neuronal activity-induced expression of Arc (1) increases endogenous nuclear Tip60 puncta, (2) recruits Tip60 to PML bodies, and (3) increases histone acetylation of Tip60 substrate H4K12, a learning-induced chromatin modification. These mechanisms point to an epigenetic role for Arc in regulating memory consolidation.
\end{abstract}

Key words: chromatin modification; epigenetics; histone acetylation; immediate early gene; synaptic plasticity

\section{Significance Statement}

This manuscript reports a novel epigenetic role for the neuronal immediate early gene Arc, a master regulator of synaptic plasticity and critical effector of memory consolidation. Arc protein is localized both to synapses, where its role is well studied, and to the nucleus, where its function is still obscure. We now report that Arc interacts with the histone acetyltransferase Tip60, a subunit of the NuA4 chromatin modifying complex that functions in transcriptional regulation, implicated in Alzheimer's disease. We present data showing that Arc associates with and enhances Tip60's acetylation of its substrate H4K12, an important learning-induced histone mark. This discovery of an epigenetic function of Arc may shed light on the mechanisms underlying the processes of learning and memory. 


\section{Introduction}

Long-term memory formation requires both RNA and protein synthesis (Davis and Squire, 1984; Alberini, 2009). The neuron-specific immediate-early gene Arc (Link et al., 1995; Lyford et al., 1995) plays a critical role in memory consolidation. Arc expression is induced by exposure to novel environments (Guzowski et al., 1999; Chawla et al., 2005), while efficient Arc translation requires concomitant activation of NMDA receptors and second messenger pathways associated with reward and fear (Bloomer et al., 2008). Down-regulation of Arc abrogates both late-phase long-term potentiation and memory consolidation (Guzowski et al., 2000; Plath et al., 2006).

While the synthesis, transport, and translation of Arc mRNA are well understood, less is known about the functions of Arc protein. One discovered role of Arc is in the regulation of AMPA receptor endocytosis, thus controlling activity-dependent synaptic efficacy (Chowdhury et al., 2006; Rial Verde et al., 2006; Shepherd et al., 2006). Recent results indicate a role for Arc in tagging inactive synapses (Okuno et al., 2012) and eliminating synaptic contacts in cerebellar development (Mikuni et al., 2013).

A significant proportion of Arc protein localizes to the nucleus (Bloomer et al., 2007), where it interacts with a nuclear spectrin isoform ( $\beta$ SpIV $\Sigma 5$ ), and associates with PML (Promyelocytic Leukemia) bodies, sites of transcriptional regulation (Torok et al., 2009). Coexpression of Arc and $\beta$ SpIV $\Sigma 5$ synergistically increase the number of nuclear PML bodies, suggesting that Arc may regulate PML body function (Bloomer et al., 2007). Increased neuronal activity promotes Arc nuclear localization, an increase in nuclear PML bodies, and reduced transcription of the GluA1 AMPA receptor, thereby contributing to homeostatic plasticity (Korb et al., 2013).

The implication of Arc in memory consolidation and transcriptional regulation, along with its nuclear localization, hints at a role in the epigenetic regulation of gene expression, which has been proposed as a mechanism for long-term memory formation (Zovkic et al., 2013). An

Received September 10, 2014; accepted November 10, 2014; First published November 12, 2014.

${ }^{*}$ C.L.W., S.T., and N.E.O. contributed equally to this work

${ }^{1}$ The authors report no financial conflicts of interest.

${ }^{2}$ Author contributions: A.M.J.V. designed research; C.L.W., S.T., N.E.O., G.D.W., and H.M.A.V. performed research; C.L.W., S.T., N.E.O., G.D.W., H.M.A.V., and A.M.J.V. analyzed data; C.L.W., S.T., N.E.O., G.D.W., and A.M.J.V. wrote the paper.

${ }^{3}$ This work was supported by Grant MOE2012-T2-1-039 from the Singapore Ministry of Education to A.M.J.V.D. and an award from the Singapore Ministry of Health and A*STAR, the Agency for Science, Technology and Research. The SIM experiments were performed at the IMB Microscopy Unit, Institute of Medical Biology, A*STAR. The STED and STORM experiments were performed at the SingHealth Advanced Bio-imaging Core facility.

Correspondence should be addressed to Antonius M.J. VanDongen at Duke-NUS Graduate Medical School, 8 College Road, Singapore 199857. E-mail: antonius.vandongen@duke-nus.edu.sg.

DOI:http://dx.doi.org/10.1523/ENEURO.0019-14.2014

Copyright (C) 2014 Wee et al.

This is an open-access article distributed under the terms of the Creative Commons Attribution License Attribution-Noncommercial 4.0 International which permits noncommercial reuse provided that the original work is properly attributed. important epigenetic modification studied in neurons is the acetylation of histones by acetyltransferases (HATs) (Peixoto and Abel, 2013). Out of the myriad of proteins that reside at nuclear PML bodies, a small number possess HAT activity (Eskiw and Bazett-Jones, 2002). These include the CREB binding protein (CBP), p300, and Tip60 (von Mikecz et al., 2000; Wu et al., 2009). CBP and p300 have both been implicated in learning and memory (Alarcon et al., 2004; Korzus et al., 2004; Barrett et al., 2011). Although brain-specific roles for Tip60 has been established in Drosophila (Pirooznia et al., 2012b; Johnson et al., 2013), little is known about its function in memory formation.

Here we report the interaction of Arc with Tip60 at nuclear PML bodies. Arc expression in hippocampal neurons induces the formation of endogenous Tip60 speckles, while Arc associates with acetylated $\mathrm{H} 4 \mathrm{~K} 12$, a known substrate of Tip60 that is critical for age-dependent memory formation (Peleg et al., 2010). Our results suggest that Arc may be recruiting the Tip60 HAT complex to modulate learning-induced $\mathrm{H} 4 \mathrm{~K} 12 \mathrm{Ac}$, and we propose a role for this complex in the epigenetic regulation of long-term memory formation.

\section{Materials and Methods}

\section{Constructs and cloning}

Arc-YFP, Arc-pCDNA3.1, PML-mCherry, PML-CFP, $\beta$ SpIV $\Sigma 5-Y F P$, and $\beta$ SpIV $\Sigma 5-C F P$ have been previously described in Bloomer et al (2007). To clone $\beta$ SpIV $\Sigma 5-$ mCherry, the YFP tag of $\beta$ SpIV $\Sigma 5$-YFP was excised with EcoRI and BsrGl and replaced with an amplified mCherry sequence containing the respective flanking sites and an in-frame stop codon. To clone $\beta$ SpIV $\Sigma 5-H A$, the YFP tag of $\beta$ SpIV $\Sigma 5$-YFP was excised with EcoRI and BsrGl and replaced with a double-stranded HA sequence containing the respective flanking sites and an in-frame stop codon. Isoform 1 of Tip60 containing flanking $\mathrm{BamH} 1$ and $\mathrm{Xho1}$ restriction sites was amplified off a first strand brain cDNA library and cloned into a pGEMT vector. Xho1-Tip60$\mathrm{BamHI}$ was then cloned into the multiple cloning site of the YFP and CFP vectors to generate Tip60-YFP.

\section{Cell culture}

Hippocampi and cortices from E18 Sprague Dawley rats of either sex were dissected aseptically and digested using a papain dissociation system (Worthington Biochemical). Cells were dissociated using a papain dissociation system (Worthington Biochemical) and plated at a density of 120,000 cells $/ \mathrm{ml}$ on poly-D-lysine-coated glass-bottom culture dishes (MatTek) that had been double-coated with poly-D-lysine. Neurons were cultured in a chemically defined medium (NBactive4; Brainbits) and fed weekly by replacing half of the medium. HEK293 cells were obtained from the Author's University Cell Culture Facility, and were cultured in high glucose DMEM (Gibco) with 10\% fetal bovine serum (Invitrogen). Like the neurons, these cells were plated on the poly-D-lysine-coated glass-bottom dishes for imaging. In addition, HEK293 cells were plated in $10 \mathrm{~cm}$ tissue culture plates for Western blots. 


\section{Transfections and stimulations}

Neuronal cultures were transfected overnight between DIV 12 and 21 using Lipofectamine 2000 (Life Technologies) per manufacturer's instructions. HEK293 cells were transfected similarly, except that DMEM with high glucose media was used and the Lipofectamine 2000/DNA mixture was added directly to existing media. For $10 \mathrm{~cm}$ cell culture dishes, $10 \mu \mathrm{g}$ of plasmid DNA plus $100 \mu \mathrm{l}$ serumfree DMEM and $10 \mu \mathrm{l}$ Lipofectamine 2000 plus $100 \mu \mathrm{l}$ DMEM were used. To stimulate protein expression of endogenous Arc or Arc constructs, forskolin at a final concentration of $50 \mu \mathrm{M}$ or the same volume of vehicle (DMSO) was added to neurons for $4 \mathrm{~h}$ before fixing. Expression of endogenous Arc was induced by stimulating spontaneous network activity in DIV18-DIV23 neurons with 4-aminopyridine (4AP, $10 \mu \mathrm{M})$ and bicuculline $(10 \mu \mathrm{M})$ for $4 \mathrm{~h}$.

\section{Immunofluorescence}

For construct coexpression experiments, transfected neurons or HEK cells were fixed with a solution containing $4 \%$ paraformaldehyde (PFA), $4 \%$ sucrose, and $1 \times$ PBS for $15 \mathrm{~min}$ at $4{ }^{\circ} \mathrm{C}$. The cells were subsequently incubated with $1 \mu \mathrm{M}$ DAPI for 10 min and preserved with FluorSave. For immunostaining, the cells were fixed with $100 \%$ $\mathrm{MeOH}$ at $-20{ }^{\circ} \mathrm{C}$ for $10 \mathrm{~min}$. Neurons/HEK cells were blocked with a solution containing $10 \%$ goat serum, $2 \%$ bovine serum albumin (BSA), and $1 \times$ PBS for $1 \mathrm{~h}$ at room temperature $(R T)$, except when goat-anti-Tip60 (K-17; Santa Cruz Biotechnology) antibody was used, in which case blocking was done with 3\% BSA in Dulbecco's PBS. The primary antibodies were incubated for $1 \mathrm{~h}$ at RT in a dilution buffer containing 1:1 block solution and PBS-Triton $\mathrm{X}$ solution at the following dilutions: mouse anti-Arc (C7), 1:300 (Santa Cruz); goat anti-Tip60 (K17), 1:300; rabbit anti-Tip60 (Novus Biologicals), rabbit anti-H4K12ac (Abcam ab61238), 1:500; rabbit-anti-PML (Abcam), 1:300; mouse-anti-PML (Sigma), 1:200. The dishes were washed two times for 10 min with PBS-Triton $X$ and incubated with Alexa Fluor 488- or Alexa Fluor 564-conjugated secondary antibodies (Invitrogen) 1:1000 in dilution buffer for $1 \mathrm{~h}$ at RT. The dishes were washed twice as above for 10 min and stained with $1 \mu \mathrm{M}$ DAPI for $10 \mathrm{~min}$ to label DNA, followed by addition of FluorSave.

\section{Imaging and data analysis}

Fluorescence images were obtained using a motorized inverted wide-field epifluorescence microscope (Nikon Eclipse Ti-E), using 40× and 60× Plan-Apo oil objectives, with numerical apertures of 1.35 and 1.49, respectively. Motorized excitation and emission filter wheels (Ludl Electronics) fitted with a DAPI/CFP/YFP/DsRed quad filter set (\#86010, Chroma) were used together with filter cubes for DAPI, CFP, YFP and TxRed, and Cy5 (Chroma) to select specific fluorescence signals. Z-stacks were obtained spanning the entire nucleus and out-of-focus fluorescence was removed using the AutoQuant 3D deconvolution algorithm (Media Cybernetics). Images were digitized using a cooled EM-CCD camera (iXon EM+ 885; Andor). Image acquisition was performed using NIS Elements AR 3.1 software (Nikon). NIS Elements analysis tools were

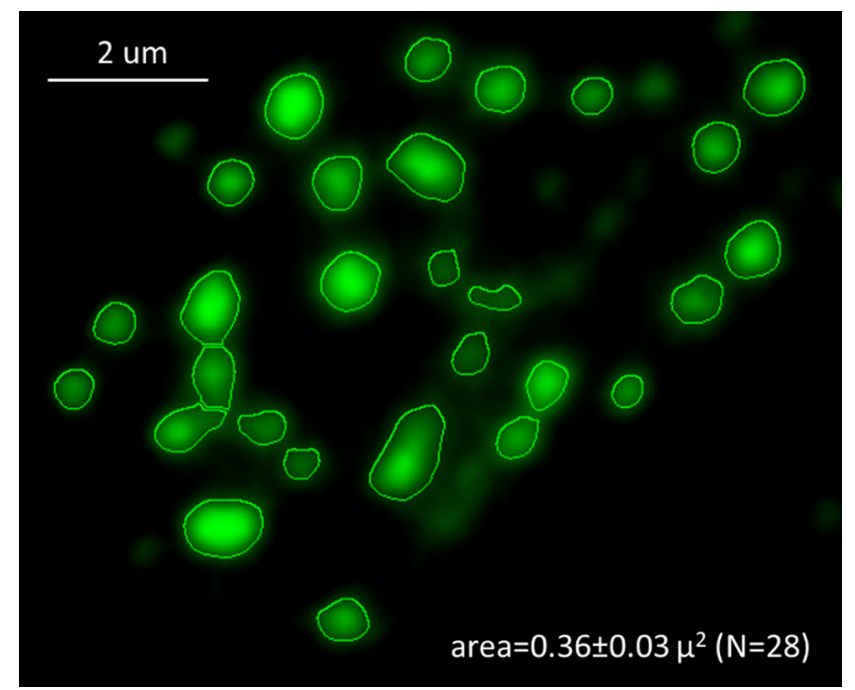

Figure 1 Segmentation of nuclear substructures. A region of interest containing Arc-YFP puncta in a single neuronal nucleus is segmented to outline the Arc structures using Elements AR. The area of each structure is calculated and the mean and SEM are reported for each nucleus, together with the number of puncta $(N)$.

used to outline the nuclei based on their DAPI images and to measure areas of the various nuclear substructures, as illustrated in Figure 1 for Arc-YFP puncta in the nucleus of a 20 DIV hippocampal neuron.

\section{$3 D$ structured illumination microscopy}

A DeltaVision OMX V4 microscope (Applied Precision-GE) equipped with 405, 488, and $568 \mathrm{~nm}$ lasers for excitation and the BGR filter drawer (emission wavelengths 436/31 for DAPI, 528/48 for Alexa488, and 609/37 for Alexa568) was used for acquisition of $3 \mathrm{D}$ structured illumination microscopy images. An Olympus Plan Apochromat 100×/ 1.4 NA oil immersion objective lens was used with liquidcooled Photometrics Evolve EM-CCD cameras for each channel. Fifteen images per section per channel were acquired (made up of 3 rotations and 5 phase movements of the diffraction grating) at a z-spacing of $0.125 \mu \mathrm{m}$, as previously described (Gustafsson, 2008; Schermelleh et al., 2008). Structured illumination reconstruction and alignment was completed using the SoftWorX (Applied Precision-GE) program with figure preparation in Fiji (Schindelin et al., 2012).

\section{Localization microscopy (PALM and STORM)}

3D photo-activated localization microscopy (PALM) and direct stochastic optical reconstruction microscopy (dSTORM) experiments were performed on the Elyra-PS.1 platform (Zeiss) with a $63 \times$ PLAN-APO objective (NA = 1.4). Excitation and dark-state conversion were facilitated by a $150 \mathrm{~mW} 642 \mathrm{~nm}$ diode laser (to excite Alexa647) and a $200 \mathrm{~mW} 488 \mathrm{~nm}$ diode laser (to excite Atto-488) operating at $100 \%$ laser power and further enhanced by ultrahigh power TIRF illumination. PALM of Arc-mEOS2 was performed by alternating excitation with a $405 \mathrm{~nm}$ laser operating in transfer mode while imaging with the $561 \mathrm{~nm}$ 
laser, whereas dSTORM used continuous excitation with the $488 \mathrm{~nm}$ and $642 \mathrm{~nm}$ laser lines and the reflected light was allowed to pass through a multi-band pass filter (set 77HE). 3D PALM/dSTORM was obtained with PRILM (phase ramp imaging localization microscopy) by placing a double phase ramp with wedge angle of 1' at the DIC slider position, which was calibrated on the day of the experiment using low density multispectral fluorescent beads $(500 \mathrm{~nm})$ to generate a Point Spread Function Localization Precision LUT. Time-lapse images were taken at $16 \mathrm{~ms}$ exposure times with the gain of the EMCCD camera set at 250 (Andor iXon DU 897). The images were cropped at $256 \times 256$ and the resulting images were processed using the PALM module of the ZEN software (Zeiss).

\section{Immunoprecipitations and Western blotting}

Transfected HEK293 cells growing in $10 \mathrm{~cm}$ tissue culture dishes were transfected as described above and allowed to express overnight at $37^{\circ} \mathrm{C}$. The cultures and subsequent lysates were kept on ice or at $4{ }^{\circ} \mathrm{C}$ throughout the entire procedure. The cultures were washed once with 1 $\mathrm{ml}$ of PBS, and lysed in $500 \mu \mathrm{l}$ of lysis buffer for $30 \mathrm{~min}$, then scraped into $1.5 \mathrm{ml}$ tubes. Lysis buffer consisted of $5 \mathrm{mM}$ HEPES pH 7.2, 0.5\% NP40, $250 \mathrm{mM} \mathrm{NaCl}, 2 \mathrm{mM}$ EDTA, $10 \%$ glycerol, 1:100 dilution of protease inhibitor cocktail (Sigma-Aldrich). The lysates were spun down for $20 \mathrm{~min}$ at $16,000 \times g$ to pellet cell debris. Lysates from multiple dishes were combined, and $1 \mathrm{ml}$ of the supernatant was then incubated on a rotator with $10 \mu \mathrm{l}$ mouseanti GFP (Roche) for $90 \mathrm{~min}$, followed by $100 \mu$ l of ProteinA/G Plus-Agarose (Santa Cruz Biotechnology) for another 60 min on a rotator. Each reaction was split into two equal volumes to allow for subsequent loading into two wells. The beads were spun down at $1000 \times g$ for $5 \mathrm{~min}$ and the supernatant was removed. The beads were washed and resuspended in $1 \mathrm{ml}$ lysis buffer. This was repeated three times. The beads and input lysates were resuspended and boiled at $95^{\circ} \mathrm{C}$ for $5 \mathrm{~min}$ in sample buffer, resolved by SDS-PAGE with Tris-glycine gels (Bio-Rad), transferred to nitrocellulose membranes (Invitrogen), and imunoblotted. The primary antibodies used were anti-GFP (rabbit polyclonal; Invitrogen), anti-Arc (rabbit polyclonal; Santa Cruz Biotechnology), or anti-HA (mouse monoclonal; Santa Cruz Biotechnology).

\section{Induction of Arc expression by stimulation of network activity}

Hippocampal and cortical neuronal cultures were grown on glass-bottom dishes (Mattek) to maturity (DIV $18-21$ ) and inspected on a brightfield microscope for formation of neurites and extensive networks. Spontaneous synaptic activity was increased in the culture on the day of the experiment for a predetermined period of time $(4 \mathrm{~h})$ by the addition of $100 \mu \mathrm{M} 4 \mathrm{AP}$, a presynaptic $\mathrm{K}^{+}$channel antagonist that facilitates transmitter release, in conjunction with $50 \mu \mathrm{M}$ bicuculline (Bic), a GABA $A_{A}$ receptor antagonist that reduces the inhibitory tone of the network. The 4AP-Bic combination increases synchronous network bursting and results in synaptic NMDA receptor activation (Hardingham et al., 2002). In order to overcome the trans- lational impediment that limits endogenous Arc protein expression, $50 \mu \mathrm{M}$ forskolin (Fors), an adenylyl cyclase activator, was added (Bloomer et al. 2008). This 4AP-Bic-Fors combination induces the expression of Arc in a subset of neurons, which is revealed by immunohistochemistry using the anti-Arc (C7, Santa-Cruz Biotechnology) antibody. At the end of $4 \mathrm{~h}$ of treatment, cultures are fixed in the presence of $4 \%$ PFA and processed for immunohistochemistry.

\section{Data analysis and statistics}

Fluorescence intensity values were determined from segmented nuclei (Fig. 1) and the mean value was calculated for each channel (Cyan, Yellow, Red, Far-red), to represent the nuclear levels of the corresponding protein, which were fluorescently labeled by antibodies (for endogenous proteins) or fusion to a fluorescent protein (CFP, YFP, mCherry) for exogenously expressed proteins. The mean and standard error of the mean (SEM) were calculated for each data set and they were compared pairwise using the Student's $t$ test for the null hypothesis that the means are identical, assuming unequal variances. Significance was evaluated using the two-tailed $p$ value and the difference between two means was considered significant when $p<0.01$. Levels of significance are denoted by asterisks: $* p<0.01, * * p<0.001, * * * p<$ 0.0001 .

\section{Results}

\section{Arc, $\beta$ SpIV $\Sigma 5$, and Tip60 form distinct, highly localized nuclear puncta}

Arc-YFP was expressed in cultured hippocampal neurons by transient transfection. Basal expression of Arc protein in cultured neurons is severely retarded due to a translation impediment, which can be rescued by activation of the cAMP-dependent protein kinase A pathway (Bloomer et al., 2008). Neurons transfected with Arc-YFP were allowed to express overnight, after which they were treated with forskolin for $4 \mathrm{~h}$ before fixation. As previously reported (Bloomer et al., 2007), a significant portion of Arc protein localizes to the nucleus, where it is enriched in puncta (Fig. 2A). These nuclear Arc puncta vary in size and number and are found in close proximity to nuclear domains densely labeled by the DNA stain DAPI (Fig. 2A, insets). At the light microscopy level, Arc and DAPI do not clearly overlap.

The neuron-specific nuclear beta-spectrin isoform $\beta$ SpIV $\Sigma 5$ has been shown to form a tight complex with PML (Tse et al., 2001) and with nuclear Arc (Bloomer et al., 2007). Expression of $\beta$ SpIV $\Sigma 5$-YFP in cultured hippocampal neurons reveals small puncta both in the cytoplasm (soma and dendrites) and nucleus (Fig. 2B). When expressed alone, the $\beta$ SpIV $\Sigma 5$ puncta are smaller in size and there are more puncta per nucleus compared to Arc. Like Arc, $\beta$ SpIV $\Sigma 5$ is often seen adjacent to DAPI-dense regions (Fig. 2B, insets). There is no clear difference in size between nuclear and cytoplasmic $\beta$ SpIV $\Sigma 5$ puncta.

When Tip60-YFP was expressed in hippocampal neurons, it was found both in the cytoplasm (mostly in the soma) and the nucleus, where it formed rather large speckles that were variable in size (Fig. 2C). Tip60 puncta 

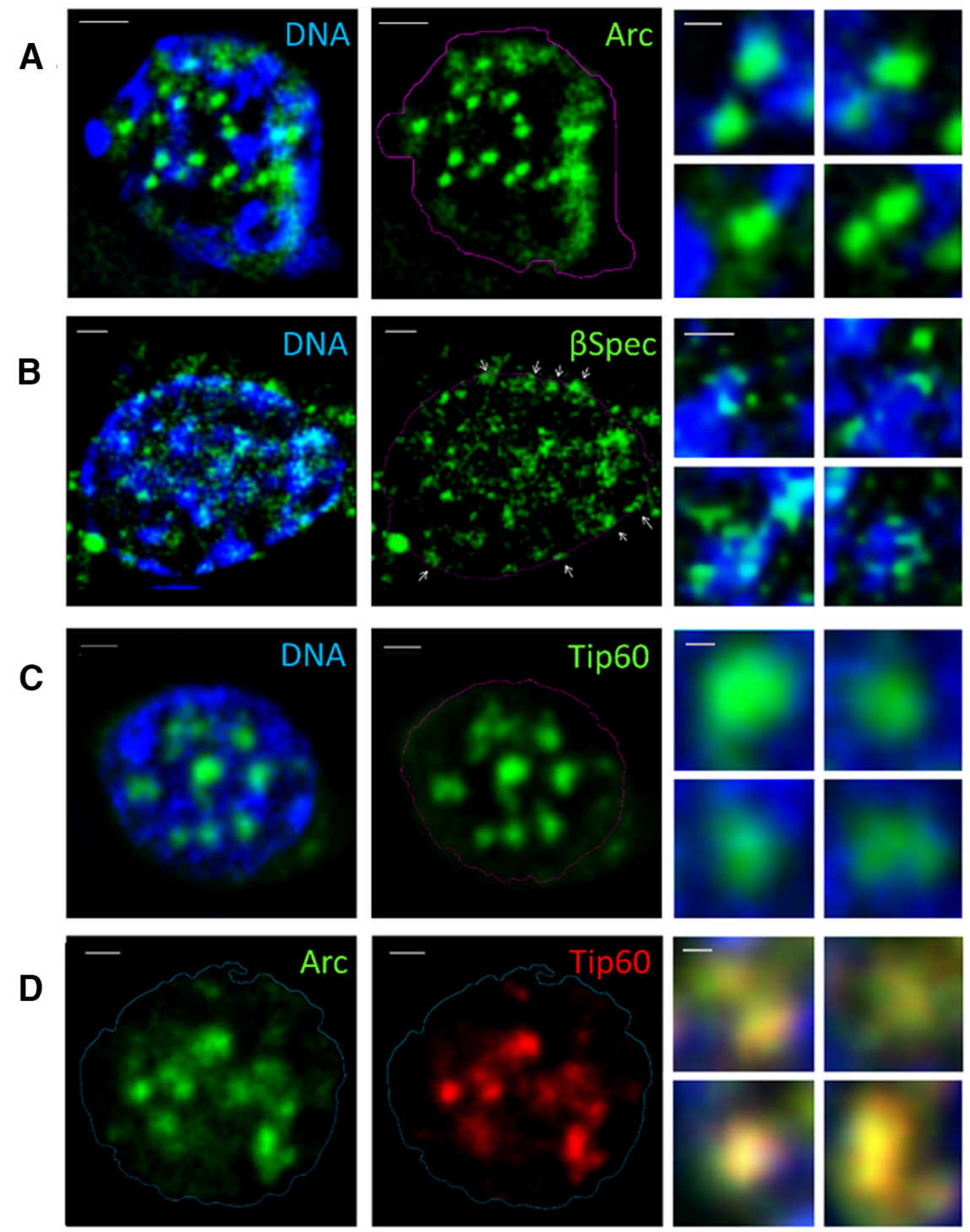

\section{$\mathbf{E}$}
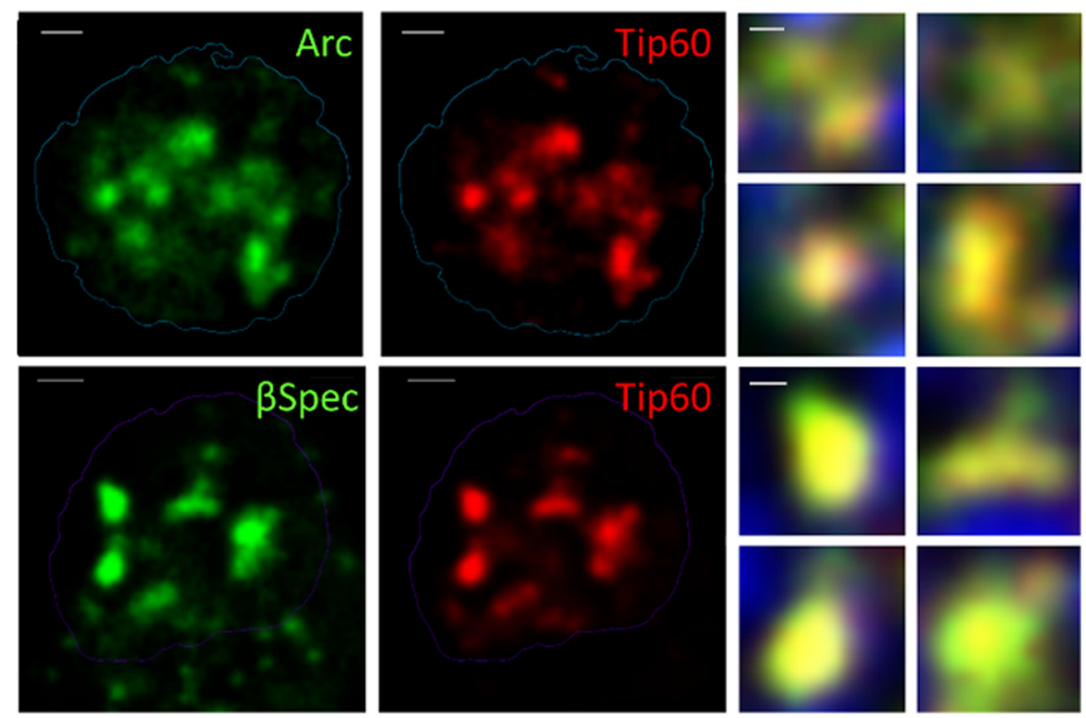

Figure 2. Arc, $\beta$-Spectrin IV ( $\beta$ Spec), and Tip60 colocalize in the nuclei of hippocampal neurons. Fluorescently tagged versions of each protein were (co-)expressed in cultured hippocampal neurons. See text for details. DNA was labeled using DAPI (blue). Wide-field z-stacks were deconvolved using AutoQuant 3D deconvolution and a representative optical section through the center of the nucleus is shown. Scale bars, $2 \mu \mathrm{m}$. Four insets on the right show the structures at higher resolution. Inset scale bars, $0.5 \mu \mathrm{m}$.

were significantly larger than those for either Arc or $\beta$ SpIV $\Sigma 5$ (Fig. 2C, inset), filling a large portion of the interchromatin space. To investigate possible interactions between these three proteins, they were fused to spectrally separated GFP isoforms and coexpressed in hippocampal neurons.

\section{Tip60 associates with both Arc and $\beta$ SpIV $\Sigma 5$}

Coexpression of Arc-YFP and Tip60-mCherry revealed a strong overlap of these two proteins in hippocampal nuclei (Fig. 2D), demonstrating colocalization of Arc with a histone-modifying enzyme. The structures that are duallabeled for both Tip60 and Arc resemble the Tip60 puncta 
(Fig. 2C) in size and number, suggesting that the Tip60 speckles have recruited Arc. The result obtained for coexpression of $\beta$ SpIV $\Sigma 5$-YFP and Tip60-mCherry was even more striking. Coexpression with Tip60 causes $\beta$ SpIV $\Sigma 5$ to redistribute from the numerous well defined small puncta to a few much larger speckles (Fig. 2E), again resembling the pattern seen for Tip60 alone. It therefore appears that Tip60 recruits both Arc and $\beta$ SpIV $\Sigma 5$ upon coexpression, changing both the size and number of their puncta.

Arc and $\beta$ SpIV $\Sigma 5$ have been shown to form a complex and each individually interacts with Tip60. We therefore coexpressed the three proteins after fusing them to spectrally distinct GFP isoforms (CFP, YFP, mCherry) in both neurons and human embryonic kidney (HEK293) cells. As illustrated in Figure 3, upon coexpression, Arc, $\beta \operatorname{SpIV} \Sigma 5$, and Tip60 form nuclear complexes in both hippocampal neurons and HEK293 cells. The fluorescence signal for the three fluorophores had a fixed ratio, indicated by the fact that almost all pixels were white, following normalization of the red, green, and blue channels. This preponderance of white pixels indicates that the stoichiometry of Arc, $\beta$ SpIV $\Sigma 5$, and Tip60 is well-defined in the complex.

A statistical analysis was performed measuring the number of puncta and their average size (area) for each nucleus (see Material and Methods). This analysis was performed for Arc, $\beta$ SpIV $\Sigma 5$, and Tip60, expressed alone or in combination. Figure 3l shows a scatterplot graphing for each nucleus, the average area of the different puncta versus their number. When expressed alone, each protein occupies a distinct region of the scatterplot (Fig. 3l). $\beta$ SpIV $\Sigma 5$ has the smallest puncta and is the most numerous, consistent with its role as a nuclear matrix protein, while Arc is intermediate in size and number, and Tip60 puncta are larger than both and are the most sparse. Coexpression of Tip $60+$ Arc, Tip $60+\beta \operatorname{SpIV\Sigma 5}$, or Tip $60+\operatorname{Arc}+\beta$ SpIV $\Sigma 5$ results in colocalization of the components to puncta, which have similar properties to those formed by Tip60 alone, indicating recruitment of all three proteins into the same complex.

\section{Arc localizes the Arc- $\beta$ SpIV $\Sigma 5-T i p 60$ complex to the perichromatin region}

As shown in the insets of Figure 2, A and B, Arc and $\beta$ SpIV $\Sigma 5$ puncta localize to interchromatin domains, but are often found adjacent to DAPI-dense structures. Figure 4 illustrates the relationship of the Arc- $\beta$ SpIV $\Sigma 5-T i p 60$ complex with DNA labeled by DAPI staining (Fig. 4A), and compares this with the localization of Tip60 (Fig. 4F) and Arc (Fig. 4K) alone, following expression of GFP fusion constructs in HEK293 cells. Arc- $\beta$ SpIV $55-T i p 60 c$ complexes appear as white puncta due to the tight colocalization of the three components. Many of these complexes localize to the interface between the interchromatin space, which is devoid of DNA, and the compact chromatin domains, which is stained heavily by DAPI. This interface is sometimes referred to as the perichromatin region, and it has important functions, including transcription and RNA processing (Fakan and van Driel, 2007; Niedojadlo et al., 2011). In several instances, the Arc-
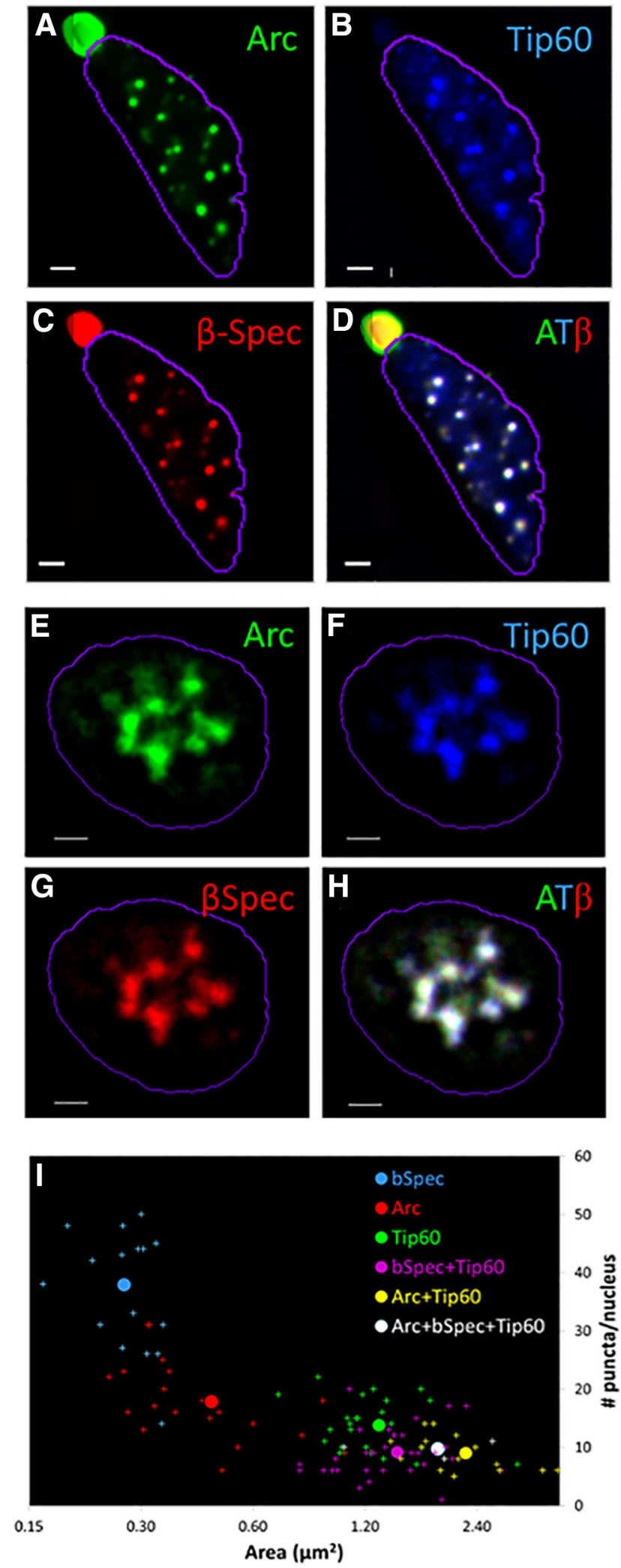

Figure 3. Arc, $\beta$-Spectrin IV ( $\beta$ Spec), and Tip60 form a tight complex. Fluorescently-tagged versions of Arc, $\beta$-Spectrin IV, and Tip60 were coexpressed in hippocampal neurons $(\boldsymbol{A}-\boldsymbol{D})$ or HEK293 cells $(\boldsymbol{E}-\boldsymbol{H})$ and imaged as described in Fig. 2. Scale bar, $2 \mu \mathrm{m}$. I, Arc, $\beta$ SpIV $\Sigma 5$, and Tip60 fused to spectrally distinct 
Figure 3. continued

GFP isoforms were expressed in hippocampal neurons, either individually, as pairs, or all three together. Neuronal nuclei were outlined using DAPI staining and subnuclear structures (puncta) were segmented as described in the Materials and Methods section. For each nucleus, the mean area and number of puncta was calculated. The scatter plot graphs number of puncta versus mean area for the different experiments. Arc, $\beta \operatorname{SpIV\Sigma } 5$, and Tip60, when expressed alone, each occupy a distinct region of the plot. Paired and tripartite complexes have properties similar to Tip60 alone.

$\beta$ SpIV 5 5-Tip60 complexes appear to be engulfed by a small amount of DAPI, indicative of loosely packed DNA characteristic of perichromatin regions. In Figure 4, the interchromatin domains are delineated by a line created by segmenting the DAPI structure to show various locations of the tripartite complex puncta: in the center of an interchromatin domain (Fig. 4B), adjacent to or embedded in the perichromatin region (Fig. 4C,D), and completely surround by chromatin (Fig. 4E). The Arc-containing complexes are seen only rarely at locations $B$ and $E$, and predominantly localize to the perichromatin regions $C D$.

In order to investigate if this interesting subnuclear localization could be attributed to an individual component of the complex, we studied their relationship with chromatin. In HEK293 cells, the tripartite complexes (Fig. 4D-E) are smaller than the Tip60 speckles (Fig. 4G-J), which filled large parts of the interchromatin space. In contrast, Arc-YFP expressed by itself in HEK293 cells (Fig. 4K) forms small puncta that localized predominantly to the perichromatin region (Fig. $4 \mathrm{~L}-\mathrm{O}$ ). Expression of Arc-YFP in hippocampal neurons (Fig. 4P) resulted in a comparable pattern where the puncta showed a strong preference for the perichromatin regions (Fig 4Q-T). When expressed by itself in neurons, $\beta \operatorname{SpIV\Sigma } 5$ forms numerous small nuclear puncta, which localize both to the interchromatin and perichromatin compartments, while a clear association with dense DAPI structure can be seen (Fig 2B).

\section{Tip60 binds to arc and $\beta$ SpIV $\Sigma 5$}

The colocalization seen in the imaging results discussed above suggests that Tip60 can bind to both Arc and $\beta$ SpIV $\Sigma 5$. To test this idea more directly, we performed coimmunoprecipitation experiments (Fig. 5). Arc was coexpressed in HEK293 cells with either Tip60-YFP, or YFP as a negative control. Tip60-YFP was immunoprecipitated with a mouse anti-GFP antibody; the precipitate was resolved by SDS-PAGE and transferred to a nitrocellulose filter, where Arc was detected with a rabbit anti-Arc antibody. These experiments showed that Arc coimmunoprecipitated with Tip60 (Fig. 5A). Tip60 was also found to bind to $\beta$ SpIV $\Sigma 5$. HEK293 cells were transfected with either $\beta$ SpIV $\Sigma 5-\mathrm{HA}$ and YFP (negative control) or $\beta$ SpIV $\Sigma 5-H A$ and Tip60-YFP. Tip60-YFP was immunoprecipitated with a mouse anti-GFP antibody, and $\beta$ SpIV $25-H A$ was detected with a mouse anti-HA antibody (Fig. 5B). Finally, Tip60 was seen to physically inter-
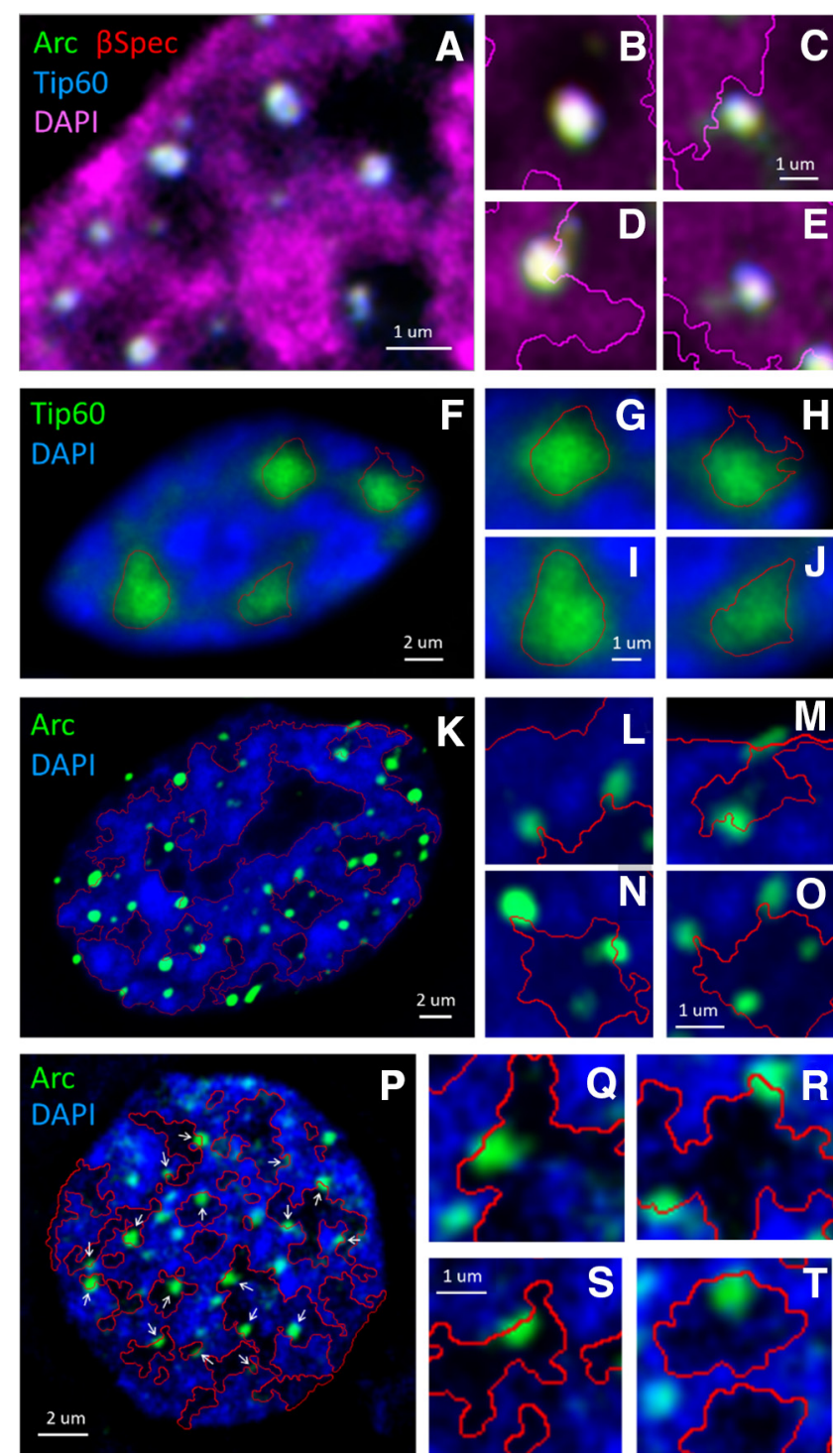

Figure 4. Arc localizes the Arc- $\beta$-Spectrin-Tip60 complex to the perichromatin region. $\boldsymbol{A}$, Fluorescently-tagged versions of Arc (green), $\beta$-Spectrin (red), and Tip60 (blue) were coexpressed in HEK293 cells and imaged as described in Fig. 3. Because of their strict overlap, Arc- $\beta$-Spectrin-Tip60 complexes appear as white puncta. The DAPI signal is shown in magenta. The insets $(\boldsymbol{B}-\boldsymbol{E})$ show the relationship between individual complexes and chromatin with higher magnification. Segmentation of the DAPI structures is indicated with a magenta line. $\boldsymbol{B}$ shows a complex in the center of an interchromatin domain. $\boldsymbol{C}$ and $\boldsymbol{D}$ show complexes localized to the perichromatin region, while $\boldsymbol{E}$ illustrates a complex surrounded by dense DAPI staining. Analysis of five nuclei indicated that the majority of puncta were localized to the perichromatin region $(84 \%, n=151)$, while the puncta were less frequently observed in the center of the interchromatin region $(9 \%, n=16)$ or in densely packed chromatin $(7 \%, n=12) . \boldsymbol{F}$, Tip60-YFP was expressed in HEK293 cells, which were fixed as stained for DNA by DAPI. Tip60 occupies large parts of the interchromatin domains. Insets $(\boldsymbol{G}-\boldsymbol{J})$ show individual Tip60 speckles in higher magnification. Not the larger size of Tip60 compared to the tripartite complexes shown in $\boldsymbol{B}-\boldsymbol{E}$. $\boldsymbol{K}$, Arc-YFP was expressed in HEK293 cells, which were fixed and stained with DAPI. Many small Arc puncta are seen, which associate with the interface of the IC domains and the dense chromatin strongly 


\section{Figure 4. continued}

labeled with DAPI, indicated with a red line that segments the DAPI structure. Insets $(\boldsymbol{L}-\boldsymbol{M})$ show the relationship of Arc puncta with chromatin at higher magnification. $\boldsymbol{P}$, Arc-YFP was expressed in hippocampal neurons (18 DIV), which were fixed and labeled with DAPI. White arrows indicate Arc puncta that localize to the interchromatin -chromatin interface indicated with the red line. Insets $(\boldsymbol{Q}-\boldsymbol{T})$ show Arc localization in higher magnification.

act with the complex formed by Arc and $\beta$ SpIV $\Sigma 5$ : HEK293 cells were transfected with Arc, $\beta$ SpIV 5 5-HA, and either YFP or Tip60-YFP. Tip60-YFP was immunoprecipitated with a mouse anti-GFP antibody, and Arc or $\beta$ SpIV $\Sigma 5-H A$ was detected with a rabbit anti-Arc or mouse anti-HA antibody, respectively (Fig. 5C), suggesting that complex formation between Arc and $\beta$ SpIV $\Sigma 5$ does not interfere with Tip60 binding.

\section{Endogenous Arc interacts with Tip60 in a rich variety of dynamic nuclear structures}

The finding that nuclear Arc colocalizes with and physically binds to Tip60 was novel and therefore prompted a more careful look into the nature of the endogenous protein-protein interactions. To this end, we employed two differing yet complementary super-resolution microscopy approaches, 3D-stimulated emission depletion microscopy (3D-STED) and 3D-stochastic optical reconstruction microscopy (3D-STORM), which push the boundaries of the resolution limit of light microscopy. Upon stimulation of network activity by a combination of $4 \mathrm{AP}$, bicuculline, and forskolin (4AP-Bic-Fors, see Materials and Methods), a subset of neurons expressed endogenous Arc, which we immunostained using an antibody recognizing Arc protein. At resolutions narrowly eclipsing $100 \mathrm{~nm}$, 3D-STED revealed that in these activated neuronal nuclei, the distribution of Tip60 protein highly paralleled that of Arc (Fig. 6, top). The two proteins abutted each other in many distinct conformations (Fig. 6, bottom). In order to definitively delineate this interaction, we proceeded to use 3D-STORM, which has the capability of imaging single molecules, and observed that in support of the results obtained through wide-field and STED microscopy, molecules of Arc and Tip60 do indeed interact in the activated neuronal nucleus with unforeseen clarity (Fig. 7).

\section{Arc increases nuclear Tip60 puncta}

To investigate the effect of Arc expression on endogenous Tip60 protein, hippocampal neurons were transiently transfected with Arc-YFP, fixed and stained with an anti-Tip60 antibody. Tip60 antibody staining in neuronal nuclei was mostly homogenous (Fig. 8A), with at most one or two detectable hotspots. However, Arc expression strongly induced the formation of bright endogenous Tip60 puncta in the nucleus (Fig. 8B,C). Figure 8 illustrates that Arc-positive nuclei contained more endogenous Tip60 puncta ( $\sim 10$ per nucleus) than untransfected controls $(0-2$ per nucleus). Although some of the Tip60 puncta were seen to associate with Arc (Fig. 8B,C, insets), the two proteins did not overlap as closely as when they were both overexpressed (Fig. 2D). Coexpression of ArcYFP and $\beta$ SpIV $\Sigma 5-C F P$ in hippocampal neurons also induced formation of extra Tip60 hotspots and the Arc$\beta$ SpIV $\Sigma 5$ complex still associated with Tip60 speckles (Fig. 8D). Our finding that Arc expression modulates the concentration of endogenous Tip60 protein in the nucleus suggests that Arc may be modulating the function of Tip60.

\section{Arc recruits Tip60 to PML bodies}

Overexpression of Arc and $\beta$ SpIV $\Sigma 5$ in HEK293 cells cooperatively increases the number of PML bodies (Bloomer et al, 2007), while regulation of transcription of the GluA1 AMPA receptor by Arc depends on PML function (Korb et al., 2013). We therefore investigated the interaction between Arc, Tip60, and PML in hippocampal neurons and HEK293 cells. When Tip60 and PML were expressed together, they both localized to the interchromatin domains, where they occupied mostly non-overlapping regions (Fig. 9A,C,E). However, when Tip60 and PML were coexpressed together with Arc, the three proteins formed a well defined complex (Fig. 9B,D,F). This recruitment of Tip60 to PML nuclear bodies was elucidated through the use of structured illumination microscopy, using HEK293 cells, which revealed that Tip60 puncta permeated and enveloped PML bodies more strongly when Arc is present (Fig. 9E).

\section{Arc increases $\mathrm{H} 4 \mathrm{~K} 12$ acetylation}

Following experimental DNA damage induction, Tip60 is recruited to PML bodies, resulting in its activation (Legube et al., 2004; Cheng et al., 2008; Wu et al., 2009). Since Arc induces a tight interaction between Tip60 and PML bodies, we investigated whether Arc expression could affect acetylation of known Tip60 histone substrates. We selected lysine 12 of histone H4, because it's the only Tip60 substrate whose acetylation is induced by learning (Peleg et al., 2010). Interestingly, learning-induced acetylation of H4K12 selectively declines with aging, and Ruvbl1, a subunit of the Tip60 complex, is shown to decrease with aging (Blalock et al., 2003).

Arc-YFP was expressed in cortical neurons for $1 \mathrm{~d}$, after which the cells were fixed and stained using an antibody specific for acetylated lysine 12 of histone $\mathrm{H} 4$ (H4K12Ac). We have performed additional experiments comparing the effect of Arc-YFP and YFP overexpression on $\mathrm{H} 4 \mathrm{~K} 12$ acetylation following treatment with forskolin, which rescues Arc translation (Bloomer et al., 2008), and the pharmacological combination of 4AP- bicuculine-forskolin, which induces endogenous Arc expression. Overexpression of YFP did not affect H4K12 acetylation, whereas Arc-YFP significantly increased H4K12 acetylation (Fig. 10B). Interestingly, the increase was much higher after network stimulation than with forskolin treatment only. In addition, these experiments revealed that endogenous Arc expression levels correlated strongly with $\mathrm{H} 4 \mathrm{~K} 12 \mathrm{Ac}$ levels. The relationship between endogenous Arc expression and $\mathrm{H} 4 \mathrm{~K} 12 \mathrm{Ac}$ levels was investigated by analyzing the $95 \%$ of the neurons that were not transfected. Segmented 

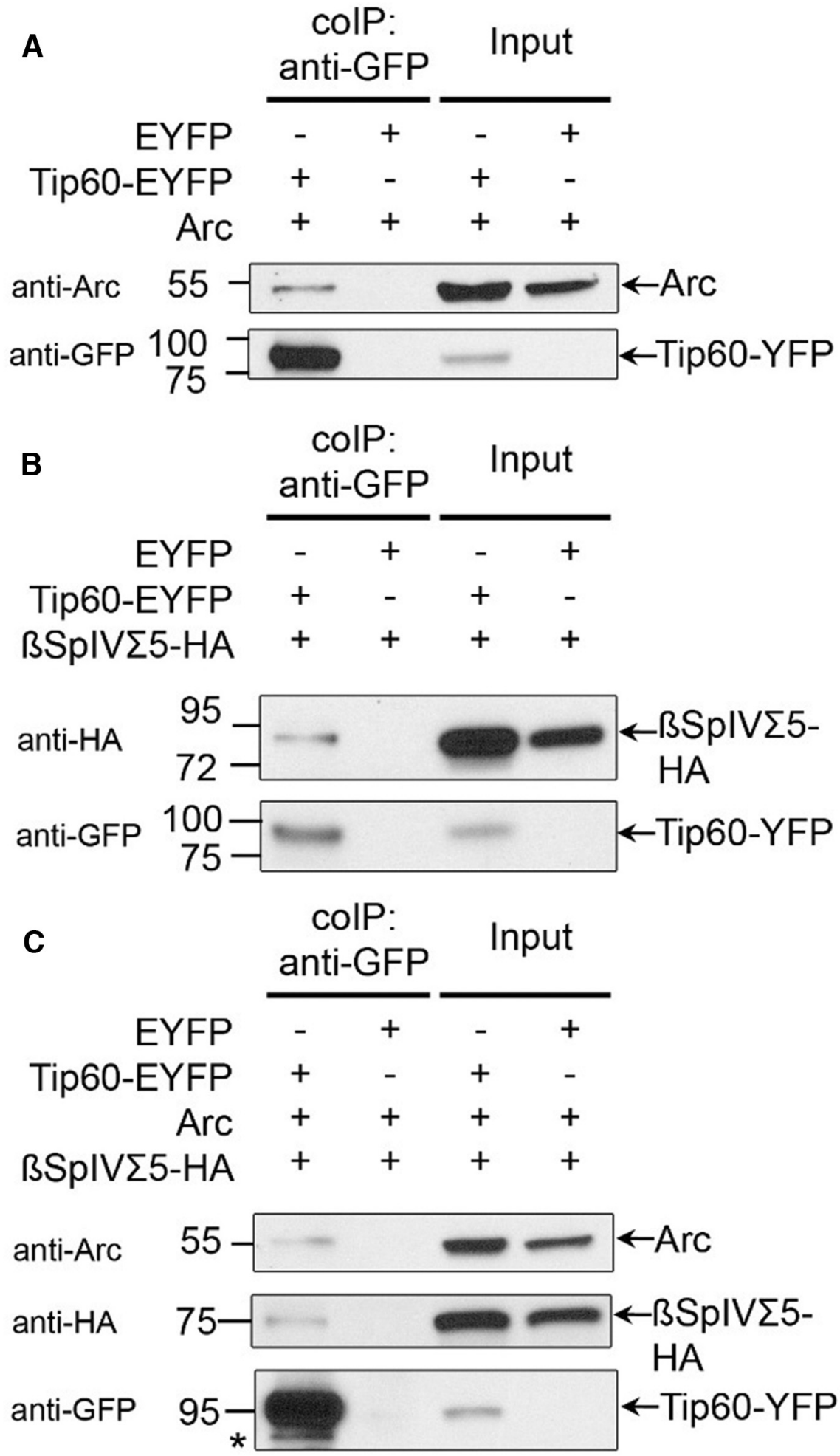

Figure 5. Arc and $\beta$ SpIV $\Sigma 5$ interact with Tip60. A, Tip60 interacts with Arc. HEK293T cells were transfected with either Arc in pCDNA3.1 and YFP vector, or Arc-pCDNA3.1 and Tip60-YFP. Tip60-YFP was immunoprecipitated with a mouse anti-GFP antibody, and Arc was detected with a rabbit anti-Arc antibody. B, Tip60 interacts with $\beta$ SpIV $\Sigma 5$. HEK293T cells were transfected with either $\beta$ SpIV $\Sigma 5-H A$ and YFP vector or $\beta$ SpIV $\Sigma 5-H A$ and Tip60-YFP. Tip60-YFP was immunoprecipitated with a mouse anti-GFP antibody, and $\beta$ SpIV $\Sigma 5-\mathrm{HA}$ was detected with a mouse anti-HA antibody. $\boldsymbol{C}$, Tip60 interacts with both Arc and $\beta$ SpIV $\Sigma 5$. HEK293T cells were transfected with Arc, $\beta$ SpIV $\Sigma 5-H A$, and either YFP or Tip60-YFP. Tip60-YFP was immunoprecipitated with a mouse anti-GFP antibody, and Arc or $\beta$ SpIV $\Sigma 5-H A$ was detected with a rabbit anti-Arc or mouse anti-HA antibody respectively. The asterix (*) denotes an unidentified band. 

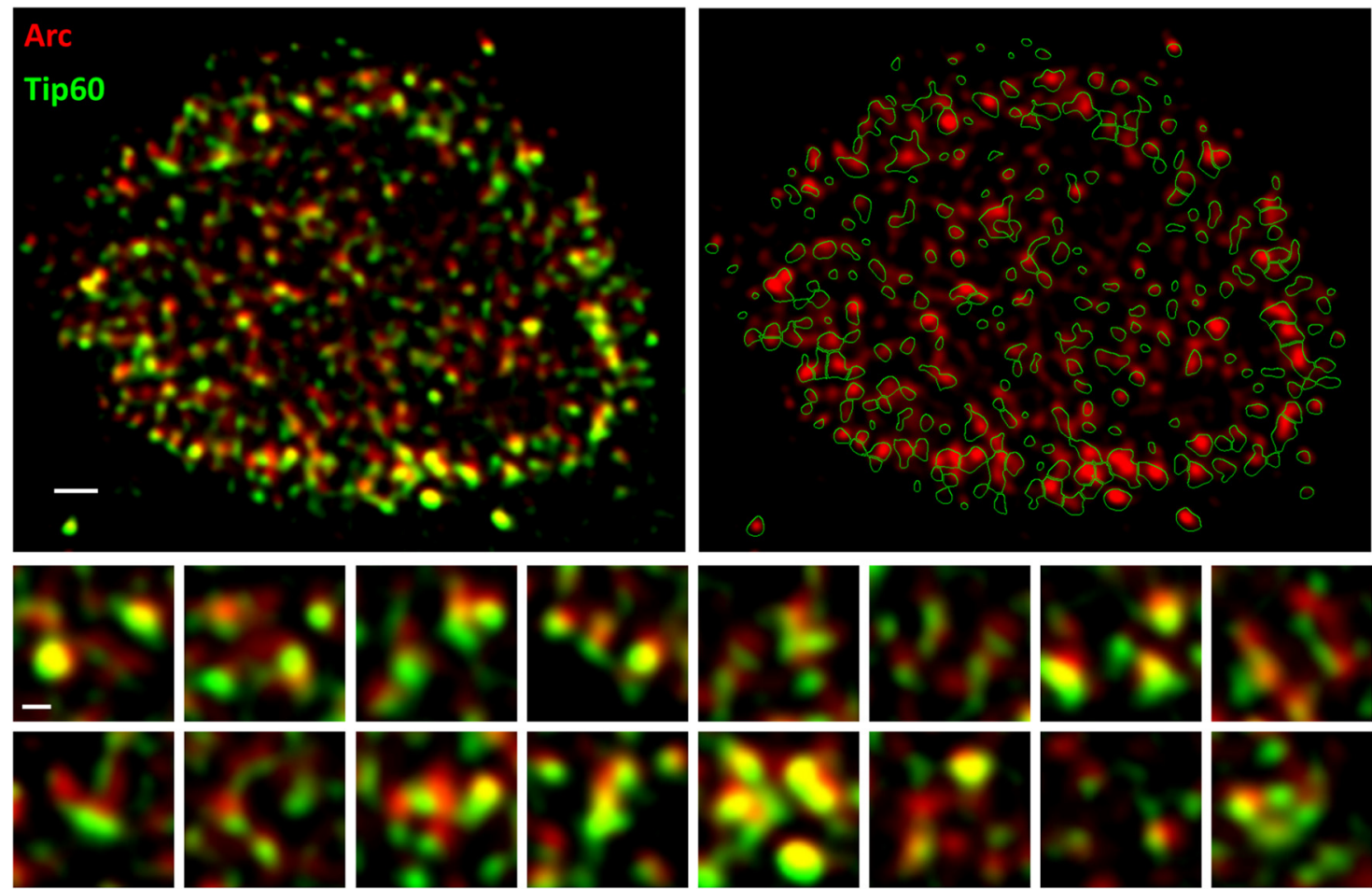

Figure 6. 3D stimulated emission depletion microscopy shows association of endogenous Arc and Tip60. The top left panel shows the distribution of endogenous Arc protein (red) and endogenous Tip60 protein (green) in a representative z-plane of a hippocampal neuronal nucleus following network activation by a $4 \mathrm{~h}$ treatment with 4AP-bicuculline-forskolin (see Materials and Methods). In the top right panel, Tip60 structures have been segmented and are shown with a green outline to highlight their relationship with Arc. Scale bar, $1 \mu \mathrm{m}$. The bottom panels show examples of the rich variety of association patterns formed by Arc and Tip60 puncta, with many unique conformations. Scale bar, $300 \mathrm{~nm}$.

nuclei were ranked according to endogenous Arc expression level and analyzed for H4K12 acetylation (Fig. 10C). The increasing trend displayed by the Arc-sorted H4K12Ac levels indicates a positive correlation between endogenous Arc levels and H4K12 acetylation status.

\section{Tip60 regulates $\mathrm{H} 4 \mathrm{~K} 12$ acetylation in hippocampal neurons}

Several enzymes, including p300, CBP, and PCAF, have been correlated to the increase of the H4K12Ac mark in the hippocampus of learning animals (Bousiges et al., $2010,2013)$, but a direct demonstration of enzyme-substrate interaction has not been reported. In order to investigate whether Tip60 may be playing a role in the acetylation of this memory-related histone mark, we expressed an enzymatically inactive mutant of Tip60Q377E/G380E (or Tip60dm for double mutant), where two critical residues in the acetyltransferase domain of the protein are mutated (Ikura et al., 2000) in hippocampal neurons. Aside from these two amino acid mutations, the chromodomain, zinc-finger domain, and the majority of the C-terminal part of Tip60 dm remain intact, resulting in an enzymatically inactive yet fully structured protein (Squatrito et al., 2006). Tip60dm therefore can be expected to act as a dominant-negative protein by associating with endogenous complexes, displacing endoTip60, and removing their histone acetyltransferase activity (Sun et al., 2005). Upon overexpression of Tip60dm, we found that the intensity of $\mathrm{H} 4 \mathrm{~K} 12 \mathrm{Ac}$ staining per nucleus was decreased, resulting in two clearly distinguishable distributions for Tip60dm-positive and -negative neurons (Fig. 11). This finding suggests that Tip60 may be one of the HATs responsible for the acetylation of H4K12 in hippocampal neurons.

\section{Arc associates with the learning-induced histone mark H4K12Ac}

The learning-induced mark $\mathrm{H} 4 \mathrm{~K} 12 \mathrm{Ac}$ is enriched in transcribed regions of gene bodies and therefore stained most of the nucleus (Fig. 12A), which made it likely to colocalize with the discrete Arc puncta (Fig. 12B) by chance alone. However, an interesting pattern emerged when the analysis was limited to H4K12Ac "hotspots", those areas in the nucleus where the $\mathrm{H} 4 \mathrm{~K} 12 \mathrm{Ac}$ signal was greater than $50 \%$ of the maximum signal (Fig. 12D,E). Arc puncta were seen to either overlap with or be adjacent to regions with the most concentrated H4K12Ac signal. Since H4K12Ac is known to be important for transcriptional elongation and each of these hotspots may correspond to several intragenic transcribed regions, we opted to analyze this association better using structured illumination microscopy (SIM). Data from SIM imaging confirmed the widefield data results. The H4K12Ac staining that appears fairly homogenous in Figure 12A actually consists of a 

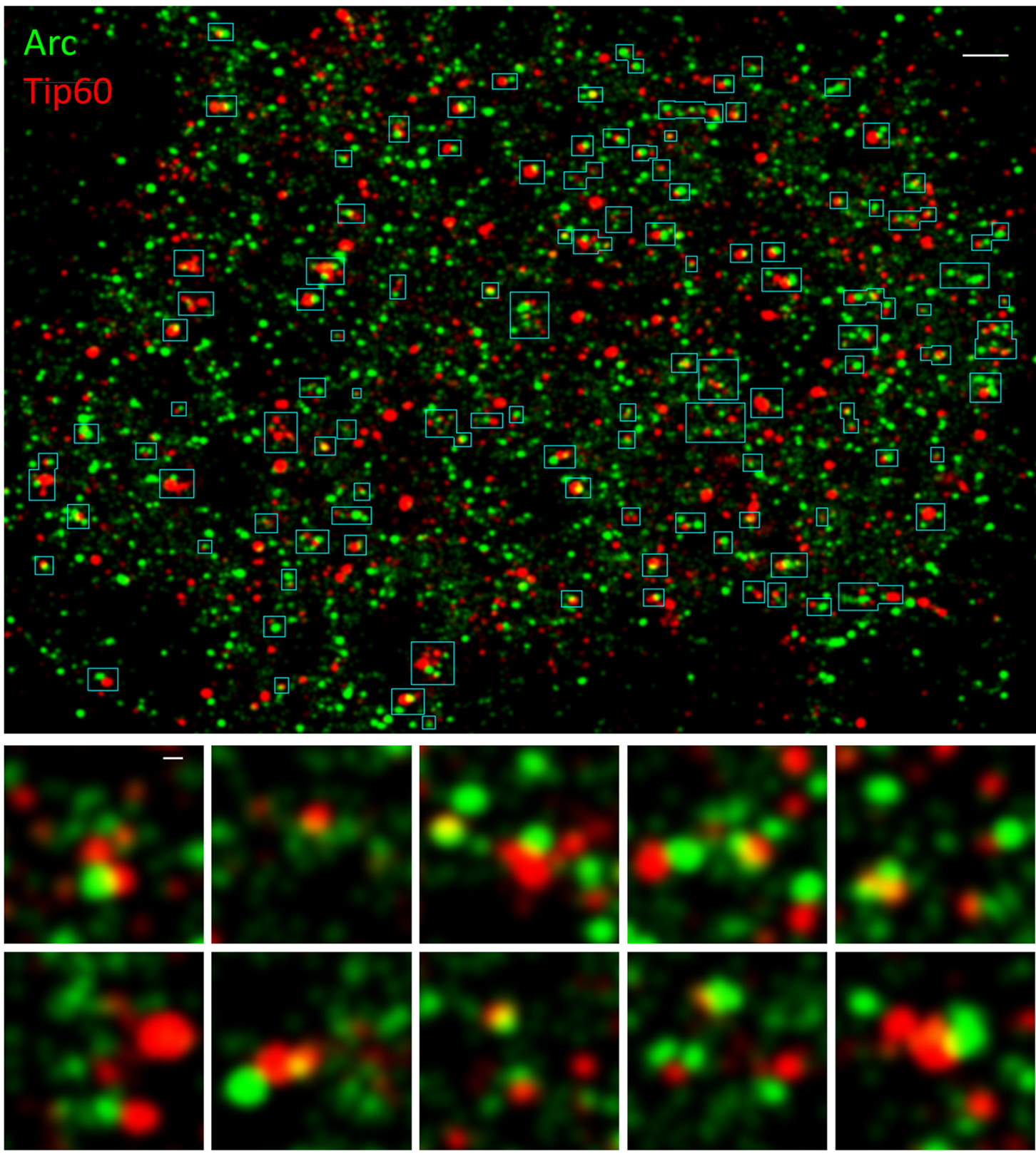

Figure 7 Dual-color super-resolution microscopy of Arc-mEOS2 and endogenous Tip60. A representative z-plane of a hippocampal neuronal nucleus after $4 \mathrm{~h}$ of network activation by 4AP-bicuculline-forskolin treatment (see Materials and Methods), showing the single-molecule distribution Arc-mEOS2 (green) imaged using 3D PALM and endogenous Tip60 (red) imaged using dSTORM. Cyan-colored squares outline distinct areas of association between Arc and Tip60 proteins, which were consistently found across reconstructed z-sections. Scale bar, $2 \mu \mathrm{m}$. The bottom panel shows detailed images at higher magnification. Scale bar, $200 \mathrm{~nm}$.

large number of very small structures, with diameters less than $200 \mathrm{~nm}$, which cannot be resolved by conventional light microscopy. The overexpressed Arc puncta maintain their solid appearance in the SIM images (Fig. 12F,G), suggesting they form large aggregates. The H4K12Ac structures were seen to cluster at several regions of the nucleus, and some of these concentrations were observed in close proximity of Arc puncta (Fig. 12G, top row). This sporadic association suggests that either Arc puncta can be recruited to pre-existing $\mathrm{H} 4 \mathrm{~K} 12 \mathrm{Ac}$ dense regions or that this histone mark may be relocated to Arc puncta.

\section{Discussion}

In this study, we report physical and functional interactions between Arc protein and the HAT Tip60. Arc not only interacts with Tip60, but also induces the formation of local concentration of endogenous Tip60. While these endogenous puncta do not interact as closely with Arc as overexpressed Tip60, they are located in close proximity. 

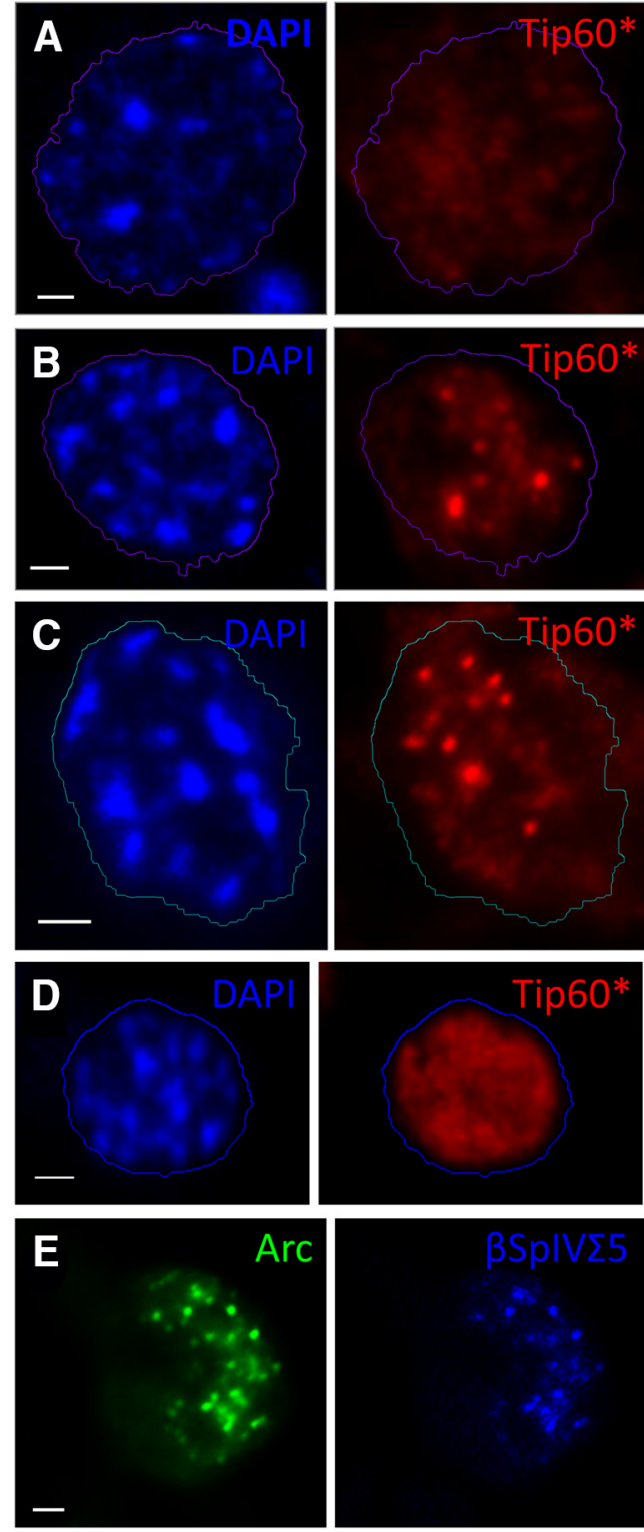
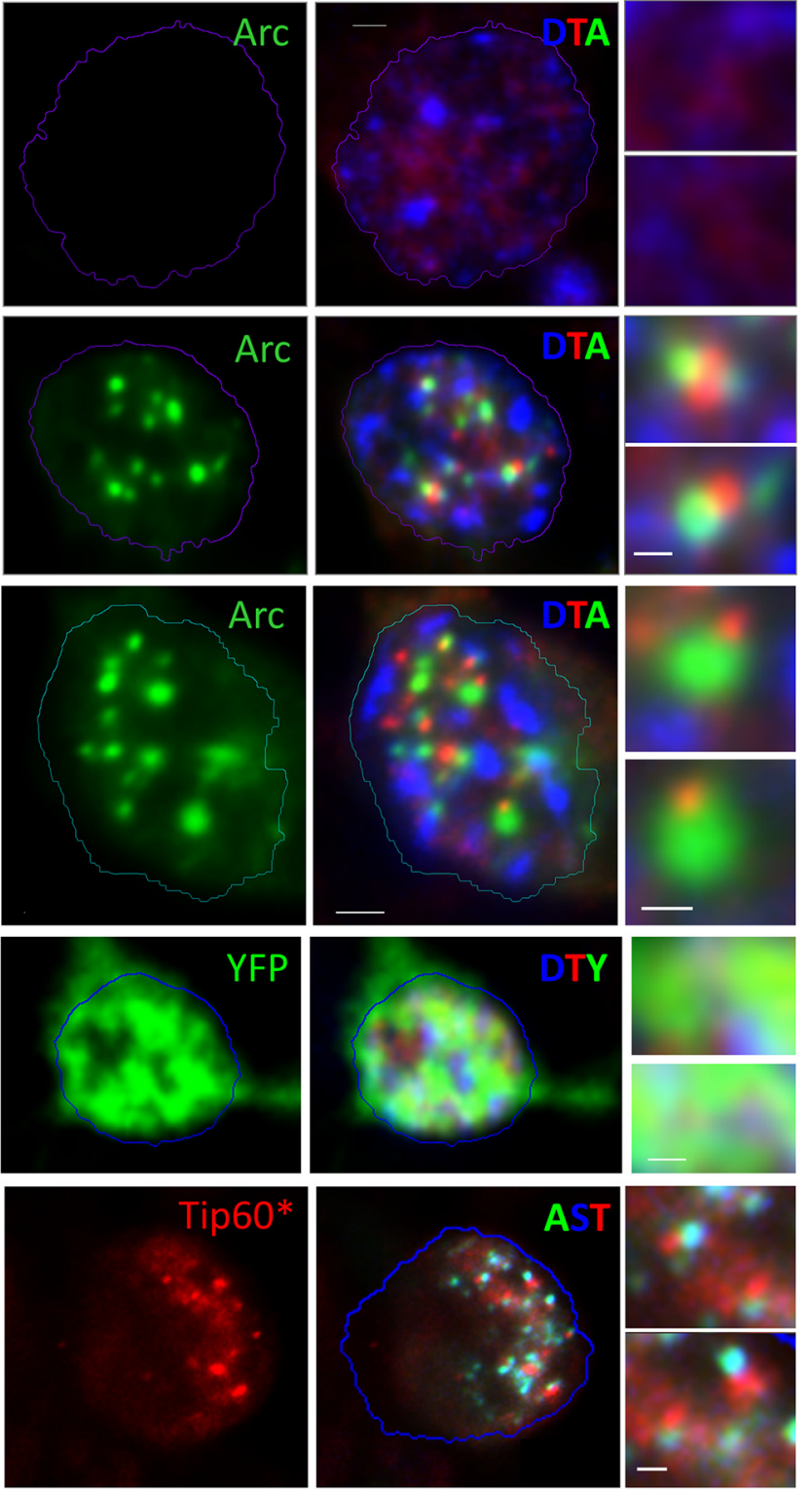

Figure 8. Arc increases nuclear Tip60 puncta. $\boldsymbol{A}-\boldsymbol{D}$, DIV18 hippocampal neurons were transfected with Arc-YFP or YFP as a control, and imaged the next day. Arc-YFP expression was stimulated for $4 \mathrm{~h}$ with $50 \mu \mathrm{M}$ forskolin or DMSO as a control, fixed and stained for endogenous Tip60 (red). Comparing Arc-negative $(\boldsymbol{A})$ with Arc-positive $(\boldsymbol{B}, \boldsymbol{C})$ neurons, it was found that overexpression of Arc-YFP induced the formation of endogenous Tip60 nuclear puncta, which associate with Arc-YFP puncta $(\boldsymbol{B}, \boldsymbol{C}$, insets). $58 \pm 4 \%(n=24)$ of endogenous Tip60 puncta were associated with exogenous Arc-YFP spots. Overexpression of YFP alone did not induce the formation of Tip60 hotspots (D). E, DIV18 hippocampal neurons were cotransfected with Arc-YFP (green) and $\beta$ SpIV $\Sigma 5-C F P$ (blue), treated for $4 \mathrm{~h}$ with forskolin, fixed and stained for endogenous Tip60 (red). Overexpression of both Arc and $\beta$ SpIV $\Sigma 5$ similarly induced the formation of endogenous Tip60 nuclear puncta, which associated with the Arc- $\beta$ SpIV $\Sigma 5$ complex. Scale bars, $2 \mu \mathrm{m}$; insets, 0.5 $\mu \mathrm{m}$. The $*$ indicates immunostaining of endogenous protein.

Tip60 was original discovered as a HIV-Tat interacting protein (Kamine et al., 1996; Yamamoto and Horikoshi, 1997) and is a component of a multimeric nuclear complex that is involved in the acetylation of six lysines on histones, which include $\mathrm{H} 2 \mathrm{~A}-\mathrm{K} 5, \mathrm{H} 3-\mathrm{K} 14$, and $\mathrm{K} 5, \mathrm{~K} 8$, K12, and K16 of histone H4 (Kimura and Horikoshi, 1998; Cai et al., 2003; Doyon et al., 2004). Tip60 is a subunit of a chromatin remodeling complex that plays roles in transcription regulation and DNA repair. In addition to HAT activity, the Tip60 complex possesses ATPase, DNA helicase, and structural DNA binding capabilities (Ikura et al., 2000).

Several previous findings support a unique role for Tip60 in the CNS. Tip60 controls sleep in the fruit fly Drosophila by epigenetically regulating axonal growth of pacemaker cells (Pirooznia et al., 2012a), while increasing Tip60 levels rescues an axonal transport defect in an Alzheimer's disease (AD) model (Pirooznia et al., 2012b; 

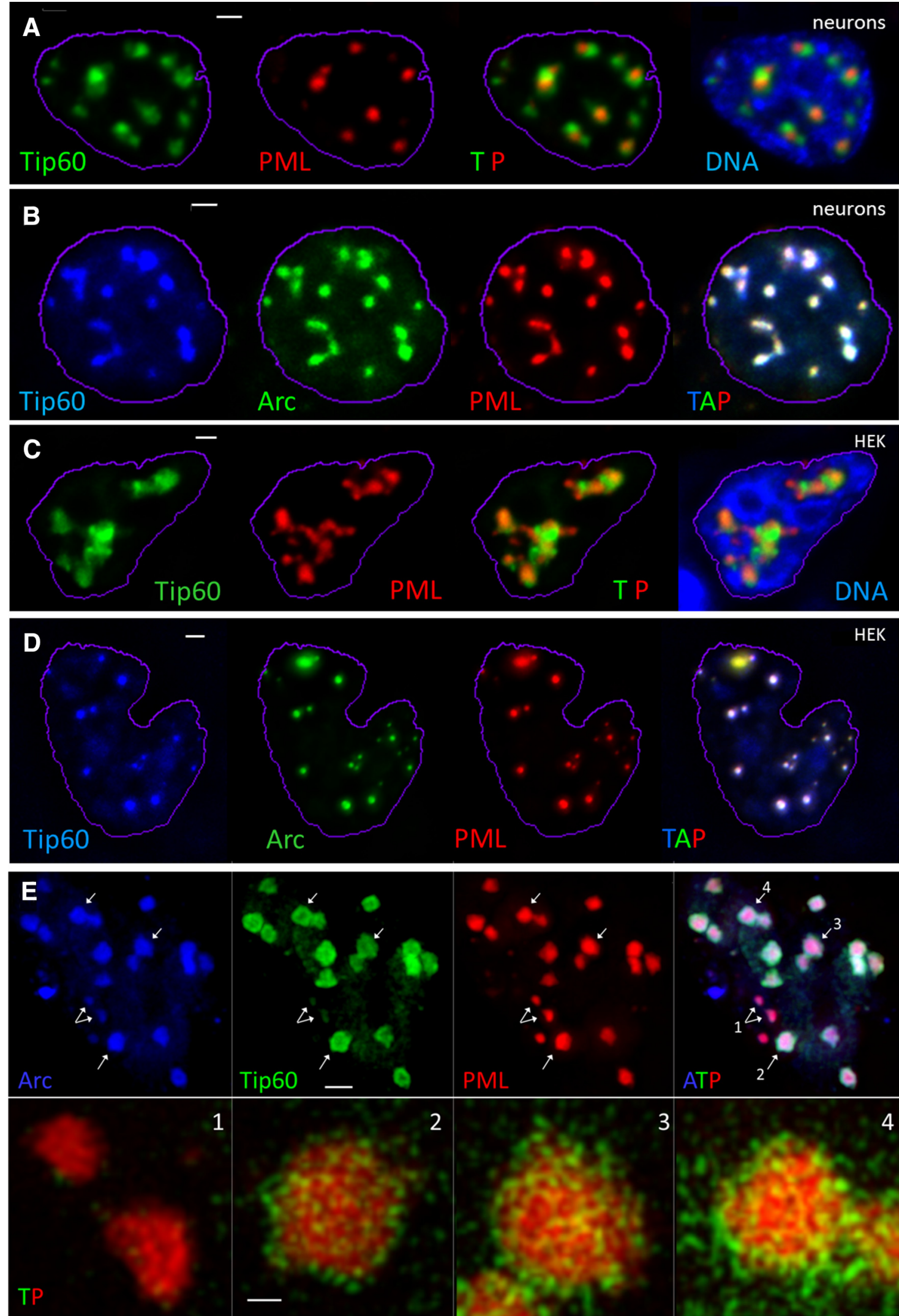

Figure 9. Arc recruits Tip60 to PML bodies. A, Tip60-YFP (green) and PML-mCherry (red) were coexpressed in 18 DIV hippocampal neurons, which were fixed and stained for DNA by DAPI (blue). Although Tip60 speckles are seen on close proximity of PML bodies in the interchromatin domains, they do not overlap. B, When Arc-YFP (green), Tip60-mCherry (blue) and PML-CFP (red) were coexpressed, they were found to tightly overlap, indicated by a puncta containing a preponderance of white pixels in the merged 


\section{Figure 9. continued}

image (far right panel). $\boldsymbol{C}, \boldsymbol{D}$, When the same experiment was performed in HEK293 cells, Tip60 and PML occupied non-overlapping regions of the interchromatin space $(\boldsymbol{C})$, while inclusion of Arc resulted in puncta in which all three proteins tightly colocalized $(\boldsymbol{D})$. $\boldsymbol{E}$, A nucleus of a representative HEK293 cell expressing Arc (blue), Tip60 (green), and PML (red), showing that in structures containing moderate to high Arc (white arrows 2 - 4) Tip60 is recruited to PML bodies, which does not occur when Arc is low (white arrow 1). The bottom insets are enlarged views of PML bodies 1-4 as viewed through structured illumination microscopy, showing that Tip60 puncta heavily populate and permeate the porous PML bodies more efficiently when Arc is present. Scale bars: $\boldsymbol{A}-\boldsymbol{D}, 2 \mu \mathrm{m} ; \boldsymbol{E}, 500$ $\mathrm{nm}$.

Johnson et al., 2013). Tip60 binds to Fe65 and AICD, the cytoplasmic C-terminal domain of APP, and the complex is targeted to the nucleus where it regulates transcription (Cao and Sudhof, 2001; Muller et al., 2013). Like Tip60, Arc has been implicated in Alzheimer's disease: patients with $A D$ can express anomalously high levels of Arc, while transgenic mouse models of $A D$ have shown that genetic deletion of Arc reduces $A \beta$ load (Wu et al., 2011), as well as disruption of experience-drive Arc responses (Rudinskiy et al., 2012). There is evidence for deregulation of epigenetic processes in $A D$, and histone modification is being considered for therapy (Stilling and Fischer, 2011).

Under basal neuronal culture conditions Arc protein expression is very low or undetectable (Bloomer et al., 2008), despite the fact that these cultures are spontaneously active (Habets et al., 1987). As both Arc and Tip60 have clear neuronal functions, we performed experiments where we induced Arc expression in hippocampal neurons by stimulating network bursting using a combination of 4AP, bicuculline, and forskolin (see Materials and Methods), which causes a subset of neurons (typically $30 \%$ ) in the network to express endogenous Arc protein. This success rate is similar to what has been seen in the dentate gyrus of animals exposed to novel environments (Chawla et al., 2005). We observed that endogenous Tip60 puncta associated with endogenous Arc protein in the neuronal nucleus. The data shown in our study therefore link Tip60 to Arc, a neuron-specific immediate early gene implicated in memory consolidation, supporting a distinctive neuronal function for Arc in regulating memory consolidation by modulating the learning-induced histone mark H4K12Ac through its association with the acetyltransferase Tip60.

\section{Dynamic nuclear interactions between Arc, $\beta$ SpIV $\Sigma$, Tip60, and PML bodies}

We demonstrate here that both Arc and $\beta \operatorname{SpIV\Sigma } 5$ can directly interact with Tip60, both separately and as a complex. Since Tip60 itself exists as a multimeric complex, it is possible that other proteins within the complex may also play a role in the Tip60-Arc interaction. For example, $\gamma$-actin and BAF53, an actin-related protein, are components of the Tip60 nuclear complex (Ikura et al., 2000), and may possibly bind to the spectrin homology domain of Arc or to spectrin $\beta S p$ IV $\Sigma 5$ itself, which may bind to nuclear actin (Young and Kothary, 2005).

We also found that the interactions between Arc, $\beta$ SpIV $\Sigma 5$, and Tip60 are dynamic, directional, and center around nuclear PML bodies. In our overexpression studies, we saw that Tip60 could cause a redistribution of Arc and $\beta$ SplV $\Sigma 5$, suggesting tight binding affinities of Arc and $\beta$ SpIV $\Sigma 5$ for Tip60. Interestingly, Tip60 has been shown to cause the redistribution of various other Tip60binding proteins to nuclear speckles, sometimes even from the cytoplasm (Legube et al., 2004; Logan et al., 2004; von Rotz et al., 2004). In contrast, expressing both Arc and $\beta$ SpIV $\Sigma 5$ together could exert a morphological change on Tip60 nuclear structure, where Tip60 no longer exists as large speckles but as round puncta that completely colocalize with Arc and $\beta \operatorname{SpIV} \Sigma 5$, which localize to the perichromatin regions, sites of transcription and RNA processing (Fakan and van Driel, 2007; Niedojadlo et al., 2011). Images taken of activated neuronal nuclei show that endogenous Arc and endogenous Tip60 strongly associate with each other and colocalize in the perichromatin region where only a select few proteins, including PML, are known to reside (Cmarko et al., 2003). Furthermore, while Tip60 and PML rarely overlap, Arc expression forms a complex with Tip60 that colocalizes tightly with PML bodies, suggesting a possible role of Arc in recruiting Tip60 to these known sites of transcription. Indeed, super-resolution imaging data presented here indicate a possible dose-dependent recruitment of Tip60 to PML bodies by Arc protein (Fig. 9).

The interaction between Tip60 and Arc is reciprocal: overexpression of Tip60 recruits coexpressed Arc to the interchromatin domain, thereby increasing its size and reducing the number of puncta (Fig. 3l). Overexpression of Arc also alters the distribution of endogenous Tip60 by causing it to form local hotspots (Fig. 8B,C). This effect of Arc on Tip60 was not seen when both were overexpressed. Overall, our results suggest that that the Arc complex may be able to recruit and redistribute Tip60 at a subnuclear level.

Overexpressed Arc puncta (Figs. 2A, 4P) were significantly larger than endogenous Arc structures (Fig. 6). The subnuclear localization of endogenous Arc proteins probably depends on its binding partners, only a few of which are known. It is possible that overexpression of Arc exhausts the pool of available binding partners, resulting in mislocalization. In this respect, our data obtained using STED microscopy of endogenous Arc and Tip60 confirms their association in a biologically relevant context.

\section{A possible epigenetic role for Arc via Tip60}

Studies of Arc's functional roles have focused on the synapse, where it regulates AMPA receptor endocytosis. Only a handful of papers so far have implicated Arc as a nuclear protein. Arc has been demonstrated to interact with Amida, a nuclear apoptosis-inducing protein, and 
A
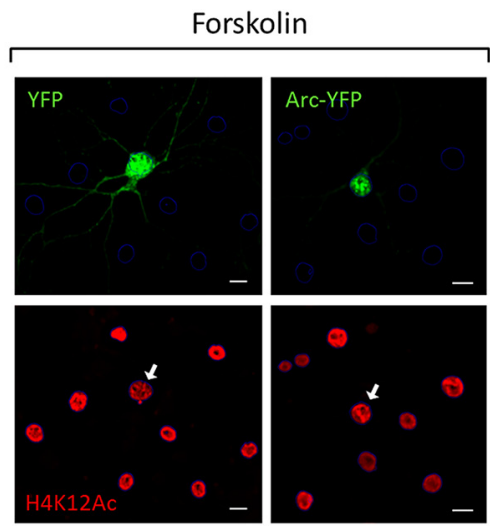

B
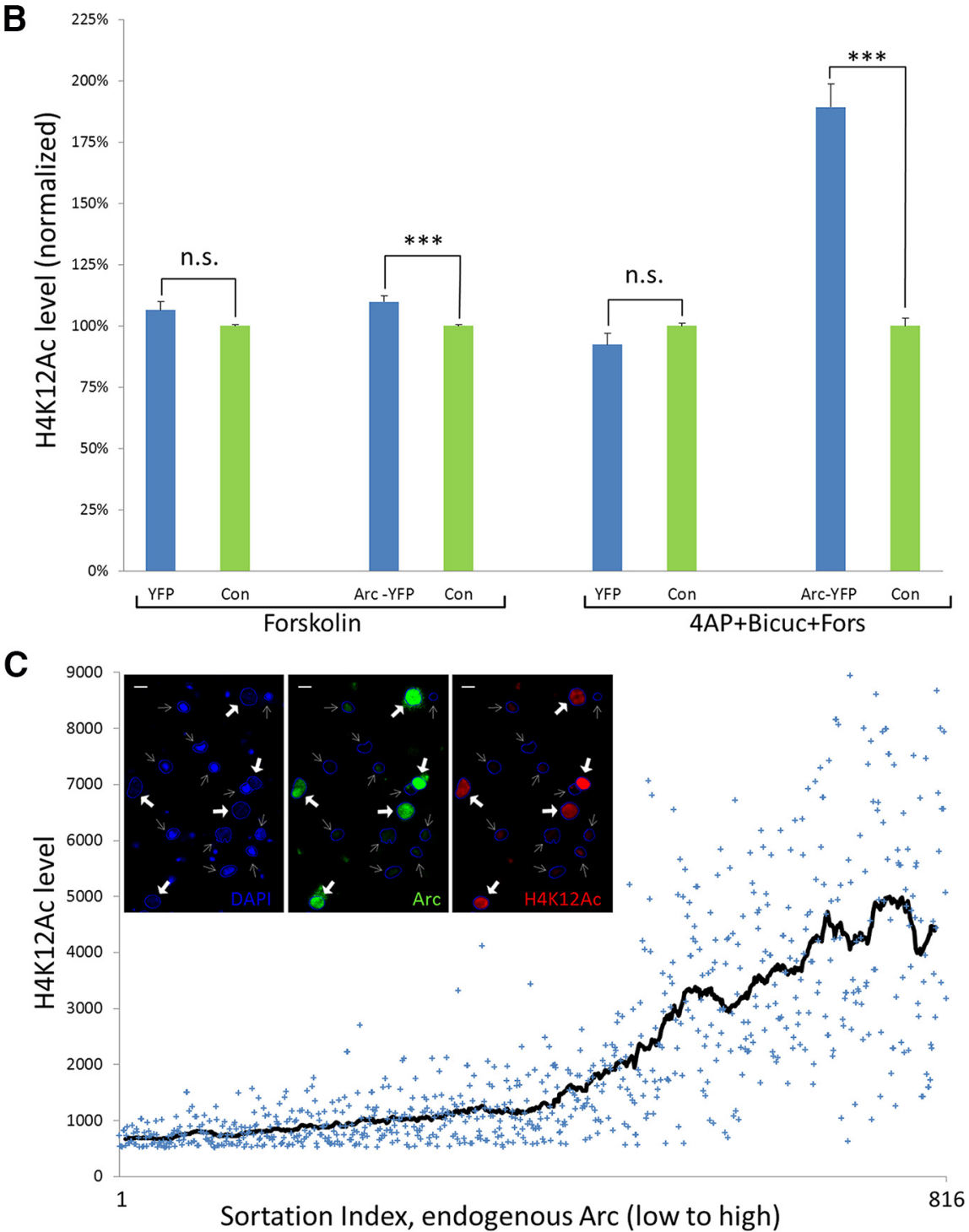

Figure 10 Arc expression increases H4K12Ac levels. Cortical neurons (21 DIV) were transfected with Arc-YFP or YFP as a control. The next day, the cultures were treated with either forskolin or the combination of 4AP-bicuculline-forskolin (see Materials and Methods for details). After $4 \mathrm{~h}$ of treatment, the neurons were fixed and stained for both H4K12Ac and endogenous Arc, using a red and far-red secondary antibody, respectively. DNA was labeled using DAPI. Scale bars, $10 \mu \mathrm{m}$. $\boldsymbol{A}$, Representative images for the four experimental conditions. Each field contains a transfected neuron (YFP or Arc-YFP) surrounded by untransfected controls. The top row shows the YFP or Arc-YFP signal, and the bottom row represents the H4K12Ac signal. The transfected neuron is indicated with a white arrow. Nuclear outlines are shown as thin blue lines. B, H4K12Ac levels (mean fluorescence intensity per nucleus) were determined for both transfected neurons (YFP or Arc-YFP) and untransfected controls (Con) for both treatment conditions for 30 fields 


\section{Figure 10 continued}

of view containing at least $1-4$ transfected neurons and $30-90$ untransfected controls. The bar graph shows the average H4K12Ac levels, normalized using the mean of the untransfected neurons, with error bars indicating SEMs. YFP overexpression did not significantly alter H4K12Ac levels in either condition: $p$ values were 0.07 and 0.12 for forskolin and 4AP-Bic-Fors, respectively. Arc-YFP overexpression increased H4K12 acetylation levels for both treatment scenarios, with high statistical significance $(p=$ $3 * 10^{-5}$ for forskolin, $p=5 * 10^{-11}$ for $4 \mathrm{AP}-\mathrm{Bic}-\mathrm{Fors}$ ), although the increase was much larger following network activation by $4 \mathrm{AP}-\mathrm{Bic}-$ Fors $(89 \%)$ than with forskolin treatment only $(10 \%)$. $* * * p<0.0001$; n.s., not significant. $\boldsymbol{C}$, The relationship between endogenous Arc expression and H4K12Ac levels was investigated by analyzing the neurons that were not transfected. The inset shows DAPI, endogenous Arc, and H4K12Ac levels for 15 untransfected neuronal nuclei. Five neurons (solid white arrows) strongly expressed endogenous Arc and the same five neurons also displayed high levels of $\mathrm{H} 4 \mathrm{~K} 12$ acetylation. Eleven neurons (thin gray arrows) had barely detectable Arc levels, and H4K12Ac staining was faint as well. Nuclei are outlined by a thin blue line. The graph was generated by sorting 816 nuclei by their endogenous Arc levels and plotting H4K12Ac levels versus the sortation index, from low to high Arc levels. The solid black line is a moving average of $50 \mathrm{H} 4 \mathrm{~K} 12 \mathrm{Ac}$ values. Scale bars, $10 \mu \mathrm{m}$.

may negatively regulate Amida-induced cell death (Irie et al., 2000). However, since Arc knockout mice do not have detectable neuron damage (Plath et al., 2006), protection against cell death is unlikely to be a major function of nuclear Arc. In 2007, Arc was localized to nuclear PML bodies (Bloomer et al., 2007), which play a crucial role in transcriptional regulation. Arc and $\beta$ SpIV $\Sigma 5$ synergistically increase the number of endogenous PML bodies in HEK293 cells, suggesting a role for Arc in regulating transcription. Consistent with this earlier finding, a recent study has demonstrated that nuclear Arc regulates GluA1 transcription and homeostatic plasticity through a PMLdependent mechanism (Korb et al., 2013).

In this paper, we have identified the HAT Tip60 as a novel Arc-interacting protein, which appears to be regulated both directly and indirectly by Arc and $\beta$ SpIV $\Sigma 5$ nuclear expression. This result is interesting especially in light of recent findings implicating histone acetylation in memory consolidation, all of which involve known Tip60 substrates (Levenson et al., 2004; Levenson and Sweatt, 2005, 2006; Fischer et al., 2007; Peleg et al., 2010). One such study demonstrated that histone acetylation increases after contextual fear conditioning and is triggered by the same signal transduction mechanisms that are implicated in LTP and memory consolidation (Levenson et al., 2004). Furthermore, treatment with drugs that promote acetylation helped to enhance long-term memory formation (Vecsey et al., 2007). Recent experiments have shown that acetylation levels increase in young mice with learning, for Lysines 9 and 14 on histone $\mathrm{H} 3$, and Lysines $5,8,12$, and 16 on histone $\mathrm{H} 4$. In older mice, only acetylation of $\mathrm{H} 4 \mathrm{~K} 12$ failed to increase, suggesting that the loss of histone H4K12 acetylation is associated with agerelated memory decline (Peleg et al., 2010).

Using a pharmacological network stimulation paradigm that specifically activates synaptic NMDA receptors (Hardingham et al., 2002), we show that expression levels of endogenous Arc protein are highly correlated with acetylation of $\mathrm{H} 4 \mathrm{~K} 12$, a modification marking regions containing gene bodies and transcriptional start sites (Park et al., 2013). While causality cannot be inferred from such a correlation, we noted that overexpression of exogenous Arc is able to increase H4K12 acetylation. The extent of this effect depends on the network activation status: under basal conditions, a small but statistically significant increment is seen, while following pharmacological net- work activation, a much more robust increase in $\mathrm{H} 4 \mathrm{~K} 12$ acetylation was evident. Therefore, activity-dependent Arc expression may make a critical contribution to the modulation of this learning-induced chromatin modification. Further evidence linking Arc with $\mathrm{H} 4 \mathrm{~K} 12$ acetylation comes from our microscopy data demonstrating the close association of individual molecules of Arc with Tip60, an enzyme responsible for this epigenetic modification, as well as with regions of the chromatin densely acetylated at this histone mark. By targeting an epigenetic regulator such as Tip60, Arc would be able to more effectively control gene transcription. It will be interesting to see if H4K12 acetylation (or other substrates of Tip60) is impaired in Arc knockout animals. Taken together, our findings point toward a function of nuclear Arc in memory consolidation, which involves modulation of the learninginduced $\mathrm{H} 4 \mathrm{~K} 12 \mathrm{Ac}$ by direct association with the histone acetyltransferase Tip60. Further exploration of the interaction between Arc and Tip60 or other chromatinmodifying enzymes in the nucleus would likely shed light on the epigenetic mechanisms of memory consolidation.

\section{References}

Alarcon JM, Malleret G, Touzani K, Vronskaya S, Ishii S Kandel ER, Barco A (2004) Chromatin acetylation, memory, and LTP are impaired in CBP $+/-$ mice: a model for the cognitive deficit in Rubinstein-taybi syndrome and its amelioration. Neuron 42:947959. CrossRef Medline

Alberini CM (2009) Transcription factors in long-term memory and synaptic plasticity. Physiol Rev 89:121-145. CrossRef Medline

Barrett RM, Malvaez M, Kramar E, Matheos DP, Arrizon A, Cabrera SM, Lynch G, Greene RW, Wood MA (2011) Hippocampal focal knockout of CBP affects specific histone modifications, long-term potentiation, and long-term memory. Neuropsychopharmacology 36:1545-1556.CrossRef

Blalock EM, Chen KC, Sharrow K, Herman JP, Porter NM, Foster TC, Landfield PW (2003) Gene microarrays in hippocampal aging: statistical profiling identifies novel processes correlated with cognitive impairment. J Neurosci 23:3807-3819.

Bloomer WA, VanDongen HM, VanDongen AM (2007) Activityregulated cytoskeleton-associated protein arc/Arg3.1 binds to spectrin and associates with nuclear promyelocytic leukemia (PML) bodies. Brain Res 1153:20-33. CrossRef Medline

Bloomer WA, VanDongen HM, VanDongen AM (2008) Arc/Arg3 translation is controlled by convergent N-methyl-D-aspartate and Gs-coupled receptor signaling pathways. J Biol Chem 283:582592. CrossRef Medline

Bousiges O, Vasconcelos AP, Neidl R, Cosquer B, Herbeaux K, Panteleeva I, Loeffler JP, Cassel JC, Boutillier AL (2010) Spatial 


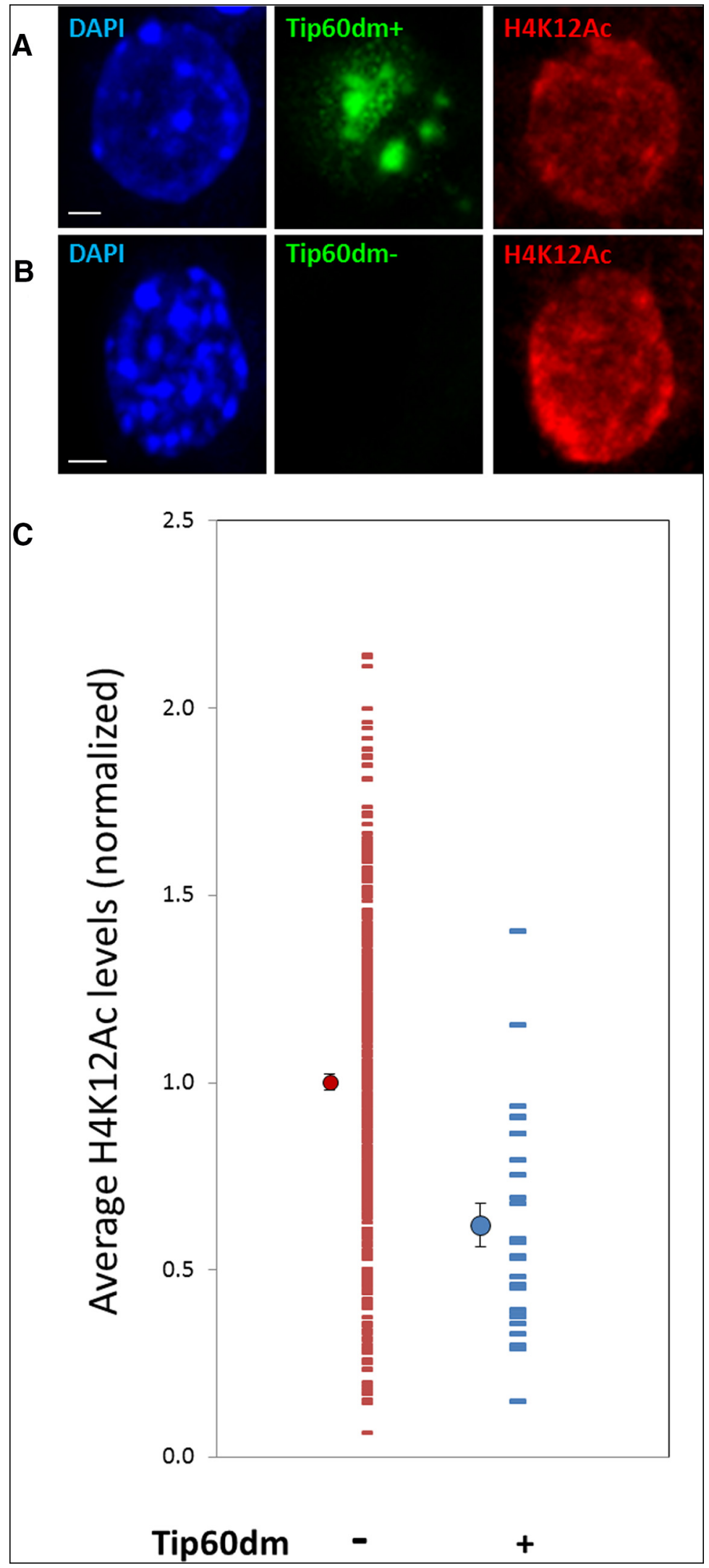

Figure 11 A Tip60 mutant lacking acetyltransferase activity decreases H4K12 acetylation. Hippocampal neurons (21 DIV) were transfected with a catalytically inactive double mutant of Tip60 (Q377E/G380E, abbreviated as Tip60dm). A, B, Representative pair of neuronal nuclei positive $(\boldsymbol{A})$ and negative $(\boldsymbol{B})$ for Tip60dm, showing that upon Tip60dm overexpression, the overall staining of 
Figure 11 continued

H4K12Ac per nucleus is decreased. Scale bars, $2 \mu \mathrm{m}$. C, Distributions of nuclear H4K12Ac staining in neurons expressing Tip60dm versus negative control neurons. Each horizontal line represents the average H4K12Ac intensity of a nucleus. All averages were normalized to the mean of the population of Tip60dm-negative neurons. Circles to the left of the distributions indicate the mean and SEM of each population: mean \pm SEM $(N)$ is $1.00 \pm 0.02(n=408)$ for Tip60dm-negative and $0.62 \pm 0.06(n=27)$ for Tip60dm-positive neurons. $p=4 * 10^{-9}$.

memory consolidation is associated with induction of several lysineacetyltransferase (histone acetyltransferase) expression levels and $\mathrm{H} 2 \mathrm{~B} / \mathrm{H} 4$ acetylation-dependent transcriptional events in the rat hippocampus. Neuropsychopharmacology 35:2521-2537.CrossRef

Bousiges O, Neidl R, Majchrzak M, Muller MA, Barbelivien A, Pereira de Vasconcelos A, Schneider A, Loeffler JP, Cassel JC, Boutillier $A L$ (2013) Detection of histone acetylation levels in the dorsal hippocampus reveals early tagging on specific residues of $\mathrm{H} 2 \mathrm{~B}$ and $\mathrm{H} 4$ histones in response to learning. PLoS One. 8:e57816CrossRef

Cai Y, Jin J, Tomomori-Sato C, Sato S, Sorokina I, Parmely TJ, Conaway RC, Conaway JW (2003) Identification of new subunits of the multiprotein mammalian TRRAP/TIP60-containing histone acetyltransferase complex. J Biol Chem 278:42733-42736.CrossRef
Cao X, Sudhof TC (2001) A transcriptionally active complex of APP with Fe65 and histone acetyltransferase Tip60. Science 293:115120. CrossRef Medline

Chawla MK, Guzowski JF, Ramirez-Amaya V, Lipa P, Hoffman KL, Marriott LK, Worley PF, McNaughton BL, Barnes CA (2005) Sparse, environmentally selective expression of arc RNA in the upper blade of the rodent fascia dentata by brief spatial experience. Hippocampus 15:579-586.CrossRef

Cheng Z, Ke Y, Ding X, Wang F, Wang H, Wang W, Ahmed K, Liu Z, Xu Y, Aikhionbare F, Yan H, Liu J, Xue Y, Yu J, Powell M, Liang S, Wu Q, Reddy SE, Hu R, Huang H, Jin C, Yao X (2008) Functional characterization of TIP60 sumoylation in UV-irradiated DNA damage response. Oncogene 27:931-941.CrossRef

Chowdhury S, Shepherd JD, Okuno H, Lyford G, Petralia RS, Plath N, Kuhl D, Huganir RL, Worley PF (2006) Arc/Arg3.1 interacts with
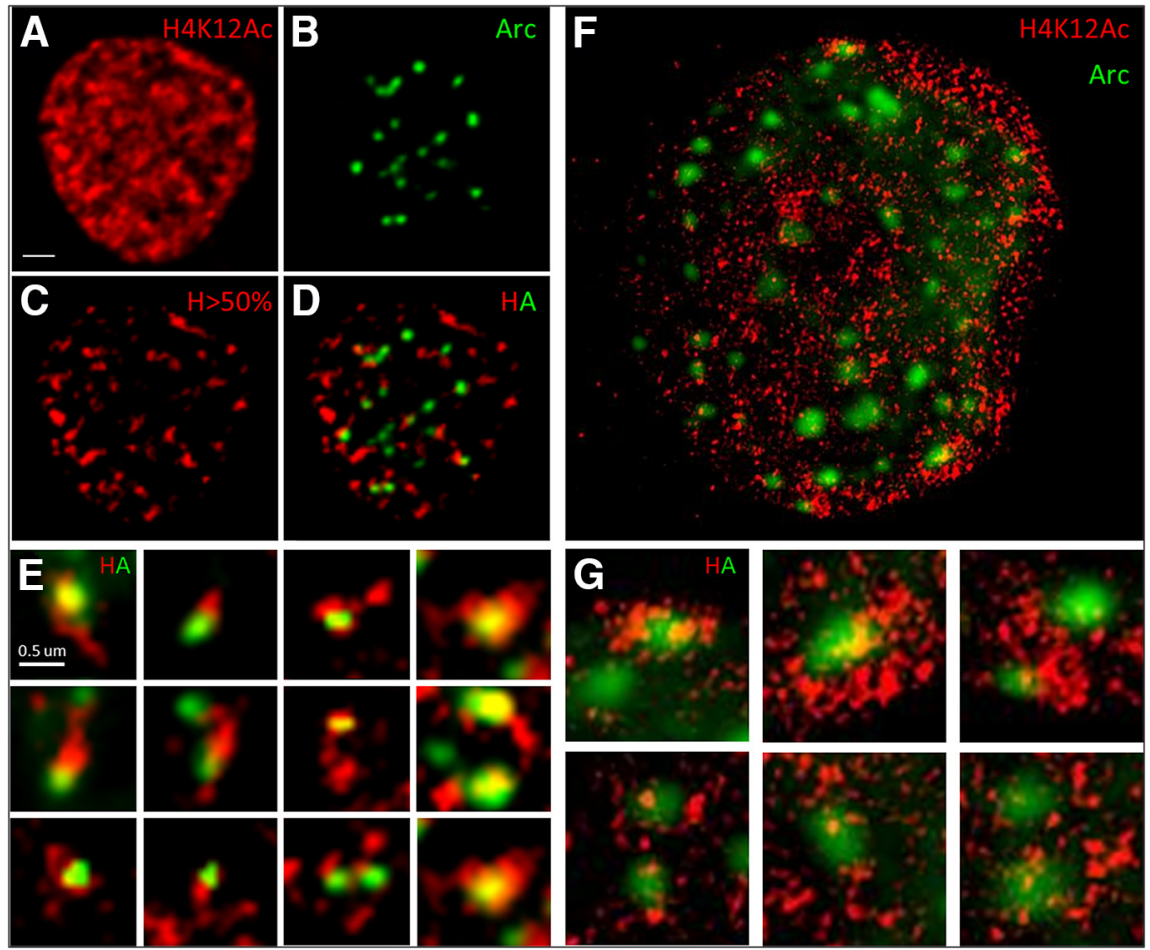

Figure 12. Arc associates with $\mathrm{H} 4 \mathrm{~K} 12 \mathrm{Ac}$. $\boldsymbol{A}-\boldsymbol{E}$, A representative hippocampal neuronal nucleus showing $\mathrm{H} 4 \mathrm{~K} 12 \mathrm{Ac}$ staining $(\boldsymbol{A})$ and Arc-YFP puncta $(\boldsymbol{B})$. The same image with increasing the brightness threshold to show only the brightest 50th percentile $\mathrm{H} 4 \mathrm{~K} 12 \mathrm{ac}$ shows clear H4K12Ac hotspots $(\boldsymbol{C})$, which is overlaid with localized Arc-YFP puncta ( $\boldsymbol{D}$; scale bar, $1 \mu \mathrm{m})$. Insets below show association of Arc puncta with H4K12ac hotspots (E; scale bar, $200 \mathrm{~nm}$ ). Hippocampal cultures were treated with 4AP, bicuculline, and forskolin for $4 \mathrm{~h}$ to induce Arc expression. $\boldsymbol{F}$, A representative image of a hippocampal neuron that has been transfected with Arc-YFP, showing Arc-YFP puncta (green), imaged with structured illumination microscopy to observe the localization of H4K12Ac (red) in higher resolution. The increased resolution afforded by SIM did not substantially change the Arc puncta. However, the H4K12Ac staining, which appeared fairly homogenous in $\boldsymbol{A}$, can now be seen to consist of many tiny structures, the size of which is just below the resolution of the conventional light microscope. They are distributed fairly uniformly over the nucleus, although local concentrations can be observed, which would correspond to the hotspots in $\boldsymbol{C}$. Some of these clusters of H4K12Ac seemed to associate with Arc puncta. Scale bar, $1.7 \mu \mathrm{m}$. G shows six Arc puncta at higher magnification. The top row shows an Arc puncta associating with dense $\mathrm{H} 4 \mathrm{~K} 12 \mathrm{Ac}$ clusters, while the bottom row shows a few bright H4K12Ac structures surrounding Arc puncta. Scale bar, $500 \mathrm{~nm}$. 
the endocytic machinery to regulate AMPA receptor trafficking. Neuron 52:445-459. CrossRef Medline

Cmarko D, Verschure PJ, Otte AP, van Driel R, Fakan S (2003) Polycomb group gene silencing proteins are concentrated in the perichromatin compartment of the mammalian nucleus. J Cell Sci 116:335-343. Medline

Davis HP, Squire LR (1984) Protein synthesis and memory: a review. Psychol Bull 96:518-559. Medline

Doyon Y, Selleck W, Lane WS, Tan S, Cote J, Doyon Y, Selleck W, Lane WS, Tan S, Cote J (2004) Structural and functional conservation of the NuA4 histone acetyltransferase complex from yeast to humans. Mol Cell Biol 24:1884-1896. Medline

Eskiw CH, Bazett-Jones DP (2002) The promyelocytic leukemia nuclear body: sites of activity? Biochem Cell Biol 80:301-310. Medline

Fakan S, van Driel R (2007) The perichromatin region: a functional compartment in the nucleus that determines large-scale chromatin folding. Semin Cell Dev Biol 18:676-681. CrossRef Medline

Fischer A, Sananbenesi F, Wang X, Dobbin M, Tsai LH (2007) Recovery of learning and memory is associated with chromatin remodelling. Nature 447:178-182. CrossRef Medline

Gustafsson MG (2008) Super-resolution light microscopy goes live. Nat Methods 5:385-387. CrossRef Medline

Guzowski JF, McNaughton BL, Barnes CA, Worley PF (1999) Environment-specific expression of the immediate-early gene arc in hippocampal neuronal ensembles. Nat Neurosci 2:1120-1124. CrossRef Medline

Guzowski JF, Lyford GL, Stevenson GD, Houston FP, McGaugh JL, Worley PF, Barnes CA (2000) Inhibition of activity-dependent arc protein expression in the rat hippocampus impairs the maintenance of long-term potentiation and the consolidation of long-term memory. J Neurosci 20:3993-4001. Medline

Habets AM, Van Dongen AM, Van Huizen F, Corner MA (1987) Spontaneous neuronal firing patterns in fetal rat cortical networks during development in vitro: a quantitative analysis. Exp Brain Res 69:43-52.CrossRef

Hardingham GE, Fukunaga Y, Bading H (2002) Extrasynaptic NMDARs oppose synaptic NMDARs by triggering CREB shut-off and cell death pathways. Nat Neurosci 5:405-414. CrossRef Medline

Ikura T, Ogryzko VV, Grigoriev M, Groisman R, Wang J, Horikoshi M, Scully R, Qin J, Nakatani Y (2000) Involvement of the TIP60 histone acetylase complex in DNA repair and apoptosis. Cell. 102:463473. Medline

Irie Y, Yamagata K, Gan Y, Miyamoto K, Do E, Kuo CH, Taira E, Miki N (2000) Molecular cloning and characterization of amida, a novel protein which interacts with a neuron-specific immediate early gene product arc, contains novel nuclear localization signals, and causes cell death in cultured cells. J Biol Chem 275:26472653. CrossRef

Johnson AA, Sarthi J, Pirooznia SK, Reube W, Elefant F (2013) Increasing Tip60 HAT levels rescues axonal transport defects and associated behavioral phenotypes in a drosophila Alzheimer's disease model. J Neurosci 33:7535-7547. CrossRef Medline

Kamine J, Elangovan B, Subramanian T Coleman D, Chinnadurai G (1996) Identification of a cellular protein that specifically interacts with the essential cysteine region of the HIV-1 tat transactivator. Virology 216:357-366. CrossRef Medline

Kimura A, Horikoshi M (1998) Tip60 acetylates six lysines of a specific class in core histones in vitro. Genes Cells 3:789-800. Medline

Korb E, Wilkinson CL, Delgado RN, Lovero KL, Finkbeiner S (2013) Arc in the nucleus regulates PML-dependent GluA1 transcription and homeostatic plasticity. Nat Neurosci 16:874-883. CrossRef Medline

Korzus E, Rosenfeld MG, Mayford M (2004) CBP histone acetyltransferase activity is a critical component of memory consolidation. Neuron 42:961-972. CrossRef Medline

Legube G, Linares LK, Tyteca S, Caron C, Scheffner M, ChevillardBriet M, Trouche D (2004) Role of the histone acetyl transferase
Tip60 in the p53 pathway. J Biol Chem 279:44825-44833. CrossRef Medline

Levenson JM, O’Riordan KJ, Brown KD, Trinh MA, Molfese DL, Sweatt JD (2004) Regulation of histone acetylation during memory formation in the hippocampus. J Biol Chem 279:40545-40559. CrossRef Medline

Levenson JM, Sweatt JD (2005) Epigenetic mechanisms in memory formation. Nat Rev Neurosci 6:108-118. CrossRef Medline

Levenson JM, Sweatt JD (2006) Epigenetic mechanisms: a common theme in vertebrate and invertebrate memory formation. Cell Mol Life Sci 63:1009-1016. CrossRef Medline

Link W, Konietzko U, Kauselmann G, Krug M, Schwanke B, Frey U, Kuhl D (1995) Somatodendritic expression of an immediate early gene is regulated by synaptic activity. Proc Natl Acad Sci U S A 92:5734-5738. Medline

Logan IR, Sapountzi V, Gaughan L, Neal DE, Robson CN, Logan IR, Sapountzi V, Gaughan L, Neal DE, Robson CN (2004) Control of human PIRH2 protein stability: involvement of TIP60 and the proteosome. J Biol Chem 279:11696-11704. CrossRef Medline

Lyford GL, Yamagata K, Kaufmann WE, Barnes CA Sanders LK Copeland NG, Gilbert DJ, Jenkins NA, Lanahan AA, Worley PF (1995) Arc, a growth factor and activity-regulated gene, encodes a novel cytoskeleton-associated protein that is enriched in neuronal dendrites. Neuron 14:433-445.CrossRef

Mikuni T, Uesaka N, Okuno H, Hirai H, Deisseroth K, Bito H, Kano M (2013) Arc/Arg3.1 is a postsynaptic mediator of activity-dependent synapse elimination in the developing cerebellum. Neuron 78: 1024-1035. CrossRef Medline

Muller T, Schrotter A, Loosse C, Pfeiffer K, Theiss C, Kauth M, Meyer HE, Marcus K (2013) A ternary complex consisting of AICD, FE65, and TIP60 down-regulates Stathmin1. Biochimica Et Biophysica Acta 1834:387-394. CrossRef Medline

Niedojadlo J, Perret-Vivancos C Kalland KH, Cmarko D, Cremer T, van Driel R, Fakan S (2011) Transcribed DNA is preferentially located in the perichromatin region of mammalian cell nuclei. Exp Cell Res 317:433-444. CrossRef Medline

Okuno H, Akashi K, Ishii Y, Yagishita-Kyo N, Suzuki K, Nonaka M, Kawashima T, Fujii H, Takemoto-Kimura S, Abe M, Natsume R, Chowdhury S, Sakimura K, Worley PF, Bito H (2012) Inverse synaptic tagging of inactive synapses via dynamic interaction of arc/Arg3.1 with CaMKIlbeta. Cell 149:886-898. CrossRef Medline

Park CS, Rehrauer H, Mansuy IM (2013) Genome-wide analysis of H4K5 acetylation associated with fear memory in mice. BMC Genomics. 14:539.CrossRef Medline

Peixoto L, Abel T (2013) The role of histone acetylation in memory formation and cognitive impairments. Neuropsychopharmacology. 38:62-76. CrossRef Medline

Peleg S, Sananbenesi F, Zovoilis A, Burkhardt S, Bahari-Javan S, Agis-Balboa RC, Cota P, Wittnam JL, Gogol-Doering A, Opitz L, Salinas-Riester G, Dettenhofer M, Kang H, Farinelli L, Chen W, Fischer A (2010) Altered histone acetylation is associated with age-dependent memory impairment in mice. Science 328:753756. CrossRef Medline

Pirooznia SK, Chiu K, Chan MT, Zimmerman JE, Elefant F (2012a) Epigenetic regulation of axonal growth of drosophila pacemaker cells by histone acetyltransferase tip60 controls sleep. Genetics 192:1327-1345. CrossRef Medline

Pirooznia SK, Sarthi J, Johnson AA, Toth MS, Chiu K, Koduri S, Elefant F (2012b) Tip60 HAT activity mediates APP induced lethality and apoptotic cell death in the CNS of a drosophila alzheimer's disease model. PLoS One 7:e41776CrossRef Medline

Plath N, Ohana O, Dammermann B, Errington ML, Schmitz D, Gross C, Mao X, Engelsberg A, Mahlke C, Welzl H, Kobalz U, Stawrakakis A, Fernandez E, Waltereit R, Bick-Sander A, Therstappen E, Cooke SF, Blanquet V, Wurst W, Salmen B, BosI MR, Lipp HP, Grant SG, Bliss TV, Wolfer DP, Kuhl D (2006) Arc/Arg3.1 is essential for the consolidation of synaptic plasticity and memories. Neuron 52:437444. CrossRef Medline

Rial Verde EM, Lee-Osbourne J, Worley PF, Malinow R, Cline HT (2006) Increased expression of the immediate-early gene arc/ 
arg3.1 reduces AMPA receptor-mediated synaptic transmission. Neuron 52:461-474. CrossRef Medline

Rudinskiy N, Hawkes JM, Betensky RA, Eguchi M, Yamaguchi S, Spires-Jones TL, Hyman BT (2012) Orchestrated experiencedriven arc responses are disrupted in a mouse model of Alzheimer's disease. Nat Neurosci 15:1422-1429. CrossRef Medline

Schermelleh L, Spada F, Leonhardt H (2008) Visualization and measurement of DNA methyltransferase activity in living cells. Curr Protoc Cell Biol Chapter 22:Unit 22.12.

Schindelin J Arganda-Carreras I, Frise E, Kaynig V, Longair M, Pietzsch T, Preibisch S, Rueden C, Saalfeld S, Schmid B, Tinevez JY, White DJ, Hartenstein V, Eliceiri K, Tomancak P, Cardona A (2012) Fiji: an open-source platform for biological-image analysis. Nat Methods 9:676-682. CrossRef Medline

Shepherd JD, Rumbaugh G, Wu J, Chowdhury S, Plath N, Kuhl D, Huganir RL, Worley PF (2006) Arc/Arg3.1 mediates homeostatic synaptic scaling of AMPA receptors. Neuron 52:475-484. CrossRef Medline

Squatrito M, Gorrini C, Amati B (2006) Tip60 in DNA damage response and growth control: many tricks in one HAT. Trends Cell Biol 16:433-442. CrossRef Medline

Stilling RM, Fischer A (2011) The role of histone acetylation in ageassociated memory impairment and Alzheimer's disease. Neurobiol Learn Mem 96:19-26. CrossRef Medline

Sun Y, Jiang X, Chen S Fernandes N, Price BD (2005) A role for the Tip60 histone acetyltransferase in the acetylation and activation of ATM. Proc Natl Acad Sci U S A 102:13182-13187. CrossRef Medline

Torok D, Ching RW, Bazett-Jones DP (2009) PML nuclear bodies as sites of epigenetic regulation. Front Biosci 14:1325-1336. Medline

Tse WT, Tang J, Jin O, Korsgren C, John KM, Kung AL, Gwynn B, Peters LL, Lux SE (2001) A new spectrin, beta IV, has a major truncated isoform that associates with promyelocytic leukemia protein nuclear bodies and the nuclear matrix. J Biol Chem 276: 23974-23985. CrossRef Medline

Vecsey CG, Hawk JD, Lattal KM, Stein JM, Fabian SA, Attner MA, Cabrera SM, McDonough CB, Brindle PK, Abel T, Wood MA (2007) Histone deacetylase inhibitors enhance memory and synaptic plasticity via CREB:CBP-dependent transcriptional activation. J Neurosci 27:6128-6140.CrossRef

von Mikecz A, Zhang S, Montminy M, Tan EM, Hemmerich P (2000) CREB-binding protein (CBP)/p300 and RNA polymerase II colocalize in transcriptionally active domains in the nucleus. J Cell Biol 150:265-273. Medline

von Rotz RC, Kohli BM, Bosset J, Meier M, Suzuki T, Nitsch RM, Konietzko U, von Rotz RC, Kohli BM, Bosset J, Meier M, Suzuki T, Nitsch RM, Konietzko U (2004) The APP intracellular domain forms nuclear multiprotein complexes and regulates the transcription of its own precursor. J Cell Sci 117:4435-4448. CrossRef Medline

Wu J, Petralia RS, Kurushima H, Patel H, Jung MY, Volk L, Chowdhury S, Shepherd JD, Dehoff M, Li Y, Kuhl D, Huganir RL, Price DL, Scannevin R, Troncoso JC, Wong PC, Worley PF (2011) Arc/ Arg3.1 regulates an endosomal pathway essential for activitydependent beta-amyloid generation. Cell. 147:615-628. CrossRef Medline

Wu Q, Hu H, Lan J, Emenari C, Wang Z, Chang KS, Huang H, Yao X (2009) PML3 orchestrates the nuclear dynamics and function of TIP60. J Biol Chem 284:8747-8759. CrossRef Medline

Yamamoto T, Horikoshi M (1997) Novel substrate specificity of the histone acetyltransferase activity of HIV-1-tat interactive protein Tip60. J Biol Chem 272:30595-30598. Medline

Young KG, Kothary R (2005) Spectrin repeat proteins in the nucleus. Bioessays 27:144-152. CrossRef Medline

Zovkic IB, Guzman-Karlsson MC, Sweatt JD (2013) Epigenetic regulation of memory formation and maintenance. Learn Mem 20:6174. CrossRef Medline 